\title{
Trilhas interpretativas em unidade de conservação: espaço pedagógico para o ensino de ecologia
}

\author{
Jean Dalmo de Oliveira Marques*, Laís Cássia Monteiro de Souza Barreto**, \\ Elizalane Moura de Araújo Marques ${ }^{\star \star \star}$
}

\section{Resumo}

A utilização de Trilhas Interpretativas (TI) em Unidades de Conservação (UC) tem sido utilizadas na educação básica e superior como alternativa viável para os conteudos ecológicos. $O$ objetivo da pesquisa foi investigar o ensino e aprendizado de Ecologia da Amazônia (EA) por meio da utilização de TI em UC, valorizando seu(s) ponto(s) de atratividade(s) e o contato do aluno com a (o) flora, solo e recurso hídrico. A metodologia utilizada teve abordagem qualitativa e utilizou uma sequência didática composta por roteiros e fichas de campo como instrumentos norteadores e questionários com mecanismo de coleta de dados. Os sujeitos da pesquisa foram 15 (quinze) alunos pertencentes ao Curso de Licenciatura em Ciências Biológicas (LCB), do Instituto Federal de Educação, Ciência e Tecnologia do Amazonas (IFAM). As TI em UC demonstraram ser eficientes espaços pedagógicos para o processo de ensino e aprendizagem de EA. Os alunos conseguiram compreender os conteúdos ecológicos, impossíveis de ocorrer em uma aula formal em sala de aula, pois as vivencias em cada TI foram cientificamente enriquecedoras, despertando valor moral, consciência crítica e percepção individual frente aos vários desafios que o Bioma Amazônia enfrenta para manter sua biodiversidade inalterada. O produto educacional elaborado contribuiu para um novo olhar a ser concebido para as UC em termos de utilização, colaborando para a instrumentalização de outros espaços com potencial para o ensino, bem como para o desenvolvimento de aulas mais participativas.

Palavras-chave: Trilha interpretativa. Unidade de conservação. Sequência didática. Ecologia da Amazônia.

- Doutor em Ecologia pelo Instituto Nacional de Pesquisas da Amazônia - INPA. Professor do Departamento Acadêmico de Química, Ambiente e Alimentos - DQA e do Programa de Pós-Graduação em Ensino Tecnológico - PPGET do Instituto Federal de Educação, Ciência e Tecnologia do Amazonas - IFAM, Brasil. E-mail: jean.marques@ifam.edu.br

* Mestre em Ensino Tecnológico pelo Programa de Pós-Graduação em Ensino Tecnológico - PPGET. Professora da Secretaria de Estado de Educação e Qualidade de Ensino do Amazonas - SEDUC - Amazonas, Brasil. E-mail: lais.cms.barreto@gmail.com

*** Mestre em Ciências de Alimentos pela Universidade Federal do Amazonas - UFAM. Professora do Departamento Química, Ambiente e Alimentos - DQA do Instituto Federal de Educação, Ciência e Tecnologia do Amazonas - IFAM, Brasil. E-mail: elizalane.marques@ifam.edu.br 


\section{Introdução}

As questões ambientais devem ser trabalhadas de forma que os alunos entendam a real importância da preservação e conservação do meio ambiente. Ao abordar estes assuntos utilizando a sua riqueza e diversidade será possível potencializar os conhecimentos transmitidos, melhorando não apenas o interesse e desempenho dos alunos nas aulas, mas também sua visão de mundo, despertando reflexões em torno dos problemas ambientais (LIMA; MARQUES, 2019).

Considerando os binômios teoria e prática, ensino e campo, esta pesquisa se pautou em uma forma de aprender e ensinar motivado pelo aprender de forma prática. Muitos conteúdos relacionados a conceitos biológicos, tais como recursos naturais, não são recentes, porém, trabalhá-los de maneira apenas teórica parece ser no mínimo negligente, circunstância esta, que pode ser um dos empecilhos para a compreensão dos conteúdos.

Dessa forma, acredita-se no papel das aulas de campo como facilitadora da aprendizagem, pois são necessárias para o entendimento do aluno quanto a vários conceitos, a saber: dinâmica, equilíbrio, uso, manejo e conservação de ambientes naturais. Contudo, existem outros aspectos que tendem a dificultar o uso de aulas práticas no processo de ensino (OLIVEIRA; CORREIA, 2013). É notório que a necessidade de práticas de campo existe, porém é perceptível um número reduzido de locais conservados nas paisagens urbanas. Assim, a falta ou a não otimização de espaços, aponta para uma descontinuidade no processo ensino e aprendizagem de Ecologia, especificamente em disciplinas que podem ser enriquecidas por práticas de campo e laboratório em áreas preservadas e/ou conservadas, como, por exemplo, em UC.

UC abertas ao público são ambientes propícios para o desenvolvimento de aulas, com enfoque nas trilhas interpretativas (TI), pois podem ser utilizadas para potencializar o processo de ensino e aprendizagem, porém é perceptível que esses espaços são escassos em ambiente urbanos. Por outro lado, muitas vezes, a própria comunidade e a academia desconhecem ambientes não formais alternativos no meio urbano que podem ser utilizados com as mais diversas finalidades. Por entender a importância das UC, a implantação de TI vem crescendo em muitas áreas (PROJETO DOCES MATAS, 2002). 
As TI desenvolvidas em UC podem enriquecer o aprendizado de estudantes e, ao mesmo tempo, contribuir para a preservação da UC, seja por meio do desenvolvimento de pesquisas ou apenas para fins de monitoramento da área. As trilhas podem ser uma fonte para trabalhar conceitos já vistos em sala de aula, principalmente quando passam pela transformação de trilhas comuns em TI, tornando possível visualizar pontos de destaque, caracterizar pontos de atratividade (PA), trabalhar temas pré-estabelecidos, desenvolver roteiros de campo, entre outros (PROJETO DOCES MATAS, 2002).

A preocupação na implantação de TI é salientada por Guimarães (2003, p. 23 apud PAIVA; FRANÇA, 2007), no sentido de que:

A trilha interpretativa como um trajeto de curta distância (500 à 1.000 metros), onde buscamos otimizar a compreensão das características naturais e/ou construídas e culturais da sequência paisagística determinada pelo seu traçado [...], direcionadas à educação ambiental, ou [...], de tomada de consciência em relação ao meio ambiente (GUIMARÃES, 2003, p. 23 apud PAIVA; FRANÇA, 2007).

As características biofísicas e estruturais de trilha merecem um detalhamento, pois são importantes para o desenvolvimento de estudos e visitas destinadas ao ensino. Prejuízos ao meio ambiente, como modificações nos aspectos topográficos e hídricos podem decorrer de trilhas mal estruturadas (COSTA, 2006). Portanto, há a necessidade de um planejamento eficaz, pensando nas características do local e o público a quem se destina as trilhas, para que possam minimizar os impactos no ambiente e maximizar o aproveitamento para o aprendizado, tendo em vista a segurança dos visitantes. Trilhas bem construídas e devidamente mantidas protegem o ambiente do impacto do uso e ainda asseguram aos visitantes maior conforto, segurança e satisfação (ANDRADE, 2003). Levando em conta tais considerações é possível instrumentalizar trilhas para proporcionar ao visitante um contato prazeroso e educativo, geralmente realizado por sinalização.

A sinalização de trilhas em ambientes naturais é de extrema importância e ainda pode levar conhecimento ao visitante. A sinalização por meio de placas é muito importante na interpretação ambiental (IA), principalmente em trilhas autoguiadas. As placas precisam ser claras, informativas, interessantes para os visitantes e contendo "textos em vários idiomas, com perguntas abertas, encorajando os visitantes a pensar e solicitando que eles façam algo, por exemplo, "olhe para cima, para ver a copa de árvores" (NELSON, 2012). 
Muitas pesquisas em ambientes naturais sobre TI têm sido desenvolvidas nos últimos anos (BEDIM, 2014; EISENLOHR et al., 2013; FEITOSA; SOUSA; ALENCAR, 2013; IKEMOTO, 2008; FILHO; AMARAL; ABREU, 2014; OLIVEIRA; MELO, 2009; SANTOS et al., 2012; SIQUEIRA, 2006; VALENTI, 2012), mas apenas com objetivo de estratégia para educação ambiental promovendo mudanças de valores e posturas em relação à natureza (SENICIATO; CAVASSAN, 2004). Reduzidos são os trabalhos que exploraram temas e conceitos vinculados ao ensino regular, com aulas práticas voltadas para o ensino (ARAÚJO et al., 2013). Quando bem demarcadas, com sinalização, com aulas planejadas e roteirizadas, podem compor um eficiente recurso para ampliação de visitas e excursões com caráter de ensino sobre os recursos naturais e conservação dos mesmos (PROJETO DOCES MATAS, 2002).

TI oportunizam ainda condições para o uso de atividades práticas de campo para auxiliar no entendimento de conceitos teóricos, tornando possível coletar amostras de solo, planta e água a serem conduzidos ao laboratório e posterior análise. São um recurso de extrema importância para o ensino e aprendizado de conteúdos ambientais que disponibilizam possibilidades para o desenvolvimento de aulas teóricas e práticas de campo, permitindo o contato direto dos alunos com os recursos naturais. Segundo Menezes (2015), uma trilha nada mais é que uma estrada para pedestres (ou em alguns casos ciclistas). Trilhas antigas em várias civilizações se tornaram rodovias existentes hoje. Todavia, atualmente, as trilhas deixaram de ser apenas um caminho para locomoção e passaram a serem utilizadas para um contato maior com a natureza (EISENLOHR et al., 2013).

Os diferentes usos dados às trilhas, hoje, têm forte relação com os apelos acerca da preservação do meio ambiente ou devido à popularidade crescente de atividades ao ar livre, como as caminhadas. Isso indica que as pessoas estão procurando novas maneiras de interagir com o ambiente natural (FERREIRA, 1998). As trilhas estão sendo utilizadas como via de condução a ambientes naturais, para contemplação da natureza, prática de esportes radicais, recreação e ecoturismo, além de ainda serem utilizadas como via de acesso e comunicação entre grupos em áreas não urbanas (COSTA et al., 2014; EISENLOHR et al., 2013).

As trilhas em locais turísticos de grande beleza cênica e em áreas conservadas são denominadas Trilhas Ecológicas (TE), pois permitem o contato dos seres humanos com o meio natural, facilitando o acesso. A crescente procura por turismo em áreas naturais faz crescer as chances de implantação de programas objetivando 
a educação ambiental nestes locais. Muitas ações de incentivo à visitação em parques e demais UC estão sendo desenvolvidas por compreender a importância que ambientes naturais tem para as relações humanas com o meio ambiente, e para que essas sejam feitas da melhor maneira (PRONEA, 2005; CASES et al., 2012; PRONEA, 2014; MENEZES, 2015).

Dentro das possibilidades dos métodos de manejo de trilhas têm-se diferentes estratégias para transformar as trilhas em oportunidades prazerosas de educação ambiental, traduzindo para o visitante os fatos que estão além das aparências, tais como leis naturais, interações, funcionamentos, história ou fatos que, mesmo aparentes, não são comumente percebidos, desenvolvendo um novo campo de percepções (ANDRETTA et al., 2006, p. 3).

As TE facilitam o contato com a natureza e as TI propõem uma experiência de aprendizagem sobre o espaço, além de proporcionarem uma maneira de entender o espaço visitado, tornando mais fácil a compreensão dos pontos de atratividade (PA), pois sem a interpretação ambiental (IA) um visitante pode passar por uma trilha e não perceber a importância da vegetação presente, dos animais, do relevo e formação geológica daquele local.

Em TI também se ressalta que é imprescindível o planejamento para que a interpretação ambiental (IA) possa ser eficiente e assim verdadeiramente levar o visitante a uma experiência educativa não-formal em determinados ambientes (PEREIRA, 2015). A IA é uma maneira de representar a linguagem da natureza, os processos naturais, a inter-relação homem e natureza, de maneira que os visitantes possam compreender e valorizar o ambiente e a cultura local (MMA, 2006). A IA tem como objeto principal as situações educativas em lugares de visitação turística, principalmente em ambientes naturais, em que se pretende alcançar alguma sensibilização e aprendizado dos visitantes para com os recursos do ambiente. Assim, a IA consiste em uma atividade praticada por guias, monitores e planejadores de instituições de turismo, preservação e conservação do patrimônio (seja ele histórico, cultural, natural etc.) (SILVA, 2012). Quando a interpretação é organizada, torna-se mais fácil de ser transmitida pelo guia e de ser entendida pelo visitante, por isso focar em um tema ajuda a selecionar os conceitos que devem ser passados para 0 visitante, facilitando a compreensão (NELSON, 2012). Essa IA é realizada a partir do mapeamento dos PA que a TI apresenta. Portanto, os PA são considerados como 
pontos de destaque que ocorrem no decorrer de uma trilha como potencial interpretativo (BARRETO; MARQUES, AZEVEDO, 2019).

A concepção de utilizar TI como estratégia para o ensino de Ecologia da Amazônia (EA) pode contribuir para melhorar o seu processo de ensino-aprendizagem e, concomitantemente, potencializar ambientes regionais que possam fomentar tal fim, com vistas à aprendizagem de componentes curriculares específicos. Sabe-se que a disciplina EA é ofertada em cursos de graduação em Biologia. Por ser específica desse curso, nas Instituições de Ensino Superior (IES) não há uma metodologia de ensino padrão estabelecida de como abordar os seus conteúdos, os quais são específicos do Bioma Amazônia (SANTOS, 2020). Portanto, utilizar trilhas se torna uma ferramenta para desenvolver aulas teóricas, práticas, transpondo a barreira do ensino fragmentado. Sendo possível abordar com mais eficácia componentes curriculares que podem ser melhor compreendidos a partir do contato do aluno com o meio ambiente.

Assim, o presente trabalho investigou o ensino e aprendizado de EA por meio da utilização de TI em UC, valorizando seu(s) ponto(s) de atratividade(s) e o contato do aluno com a flora, solo e recursos hídricos.

\section{Metodologia \\ Sujeito e local da pesquisa}

Os sujeitos da pesquisa foram 15 (quinze) alunos pertencentes ao $7^{\circ}$ e $8^{\circ}$ períodos do curso de Licenciatura em Ciências Biológicas (LCB), pertencentes ao IFAM. As TI foram abertas Ponta das Lajes, localizada na parte central da Bacia do Amazonas, coordenadas $03^{\circ} 08^{\prime} \mathrm{S}$ e 5952’W, na margem esquerda do Rio Amazonas, cerca de $20 \mathrm{~km}$ ao oeste do Rodway, porto do centro histórico da cidade de Manaus, a 2 $\mathrm{km}$ à jusante da confluência dos rios Negro e Solimões, especificamente em uma UC do tipo Reserva Particular do Patrimônio Nacional (RPPN) Dr. Daisaku Ikeda, pertencente à Associação Brasil Soka Gakkai, situado na Avenida Desembarcador Anísio Jobim 980, Km 11 (FRANZINELLI; IGREJA, 2013) (Figura 1). 
Figura 1: Mapa da RPPN Dr. Daisaku Ikeda destacando com setas vermelhas as TI abertas.

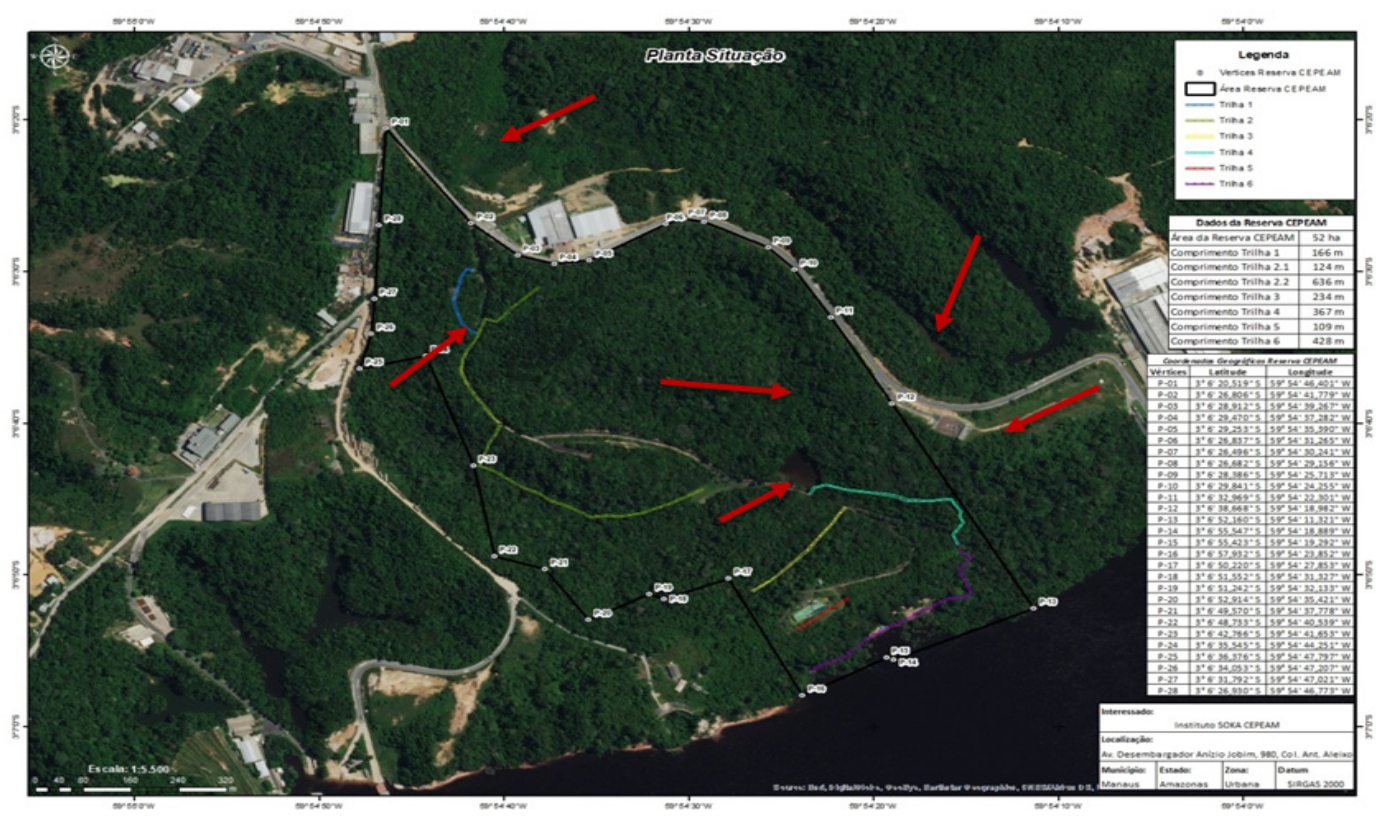

Fonte: Os autores (2020).

\section{A Pesquisa}

Esta pesquisa faz parte do projeto intitulado utilização de UC no ensino e aprendizado de recursos naturais na Amazônia. A pesquisa foi voltada para o ensino e aprendizado e teve natureza qualitativa, pois considerou o contato direto do pesquisador com o ambiente e a situação que está sendo investigada (DENZIN; LINCOLN, 2006). No mesmo sentido, tem característica de pesquisa descritiva, onde essa visa descrever as características de determinada população ou fenômeno, e faz uso de técnicas padronizadas de coleta de dados: questionário e observação sistemática (GIL, 1991; DALFOVO; LANA; SILVEIRA, 2008).

A sequência didática seguida para o desenvolvimento desta pesquisa foi planejamento; identificação, seleção e reconhecimento das trilhas; caracterização biofísica; intervenção, instrumentalização/sinalização das trilhas e verificação da aprendizagem, que serão descritas a seguir: 


\section{Identificação, seleção e reconhecimento das trilhas para interpretação}

Cada trilha recebeu um nome específico conforme o seu principal recurso natural a ser utilizado nas aulas de EA, conforme seus PA. Assim, em cada trilha avaliou-se os indicadores de atratividade que foram utilizados para definir o tema das TI. Os indicadores de atratividade foram analisados levando em conta o valor qualitativo para aumentar a atratividade do local (GONZAGA; MARTINS, 2011).

\section{Caracterização biofísica das TI}

A caracterização biofísica das TI foram realizadas para caracterizá-las em nível de dificuldade devido a possibilidade de alguns obstáculos naturais, levando em conta a acessibilidade, pois foram utilizadas por alunos de diferentes faixa etárias e condições físicas. Os níveis estipulados foram: leve, médio e difícil. Estes níveis foram construídos com a análise do comprimento, declividade e solo da trilha. Os níveis servem para instruir o visitante que farão uso das TI e essas informações estão contidas nas placas situadas na entrada das trilhas. Os parâmetros para medidas foram adaptados de Ikemoto (2008), acrescentando-se apenas o parâmetro, nível do rio, devido as condições amazônicas de variação do pulso de inundação, que direta ou indiretamente afetam as trilhas utilizadas na UC. As características biofísicas das trilhas foram verificadas por sensoriamento remoto e uso de um aparelho de posicionamento global (GPS), onde foram gerados mapas altimétricos contendo declividade, largura e comprimentos das trilhas, possibilitando a identificação das trilhas em nível de dificuldade.

\section{Intervenção}

As atividades interventivas foram realizadas durante 2 (dois) dias consecutivos, até 3 (três) trilhas por dia, obedecendo a ordem contida na Tabela 1 . Antes de ingressar nas TI, os alunos foram divididos em 3 (três) grupos contendo 5 (cinco) alunos em cada grupo sendo que cada grupo escolheu uma trilha para a qual desejava projetar as placas interpretativas (PI). Todas as atividades foram desenvolvidas com a participação direta dos alunos sob a constante orientação do professor.

Foram utilizados caderno, caneta, máquina fotográfica, quadrado de madeira $20 \mathrm{~cm} \times 20 \mathrm{~cm}$, régua, pá de jardim, saco plástico de $2 \mathrm{~kg}$, recipientes de alumínio $20 \mathrm{~cm} \times 20 \mathrm{~cm}$, estufa de $50^{\circ} \mathrm{C}$. 
Cada TI possuía um roteiro e ficha de campo especifica, onde o aluno pôde registrar suas observações. As aulas dialogadas-expositivas em cada trilha direcionavam os alunos a observarem os potenciais ecológicos.

Os roteiros específicos e as fichas de campo utilizadas para cada trilha podem ser visualizados http://repositorio.ifam.edu.br/jspui/handle/4321/356. Esses norteavam o aluno a observar as características da TI e os seus pontos de maior importância educacional registrando tais pontos por meio de fotos. Portanto, os objetivos e as estratégias planejadas seguiram as especificidades de cada trilha, já que cada uma tinha um potencial específico para ser utilizada no processo de ensino e aprendizagem (Quadro 1).

Quadro 1: Procedimentos adotados nas TI.

\begin{tabular}{|c|c|c|c|c|}
\hline $\mathrm{N}^{\circ}$ & Trilha & $\begin{array}{l}\text { Conteúdo } \\
\text { de EA }\end{array}$ & Objetivo(s) & Estratégia(s) utilizada(s) \\
\hline 1 & $\begin{array}{l}\text { Trilha Entrada } \\
\text { da Reserva } \\
\text { (TER) }\end{array}$ & $\begin{array}{l}\text { Política } \\
\text { Ambiental }\end{array}$ & $\begin{array}{l}\text { Abordar a Lei } n^{\circ} 6.938 \text { e Lei } \\
9.985 . \\
\text { Demonstrar a importância da } \\
\text { gestão eficiente em UC por } \\
\text { meio de reflorestamento e re- } \\
\text { cuperação de área degradada. }\end{array}$ & $\begin{array}{l}\text { Aula expositiva dialogada ao longo da tri- } \\
\text { lha com duração de } 30 \text { minutos na trilha. }\end{array}$ \\
\hline 2 & $\begin{array}{l}\text { Trilha Perfil } \\
\text { Topográfico } \\
\text { (TPT) }\end{array}$ & $\begin{array}{l}\text { Relevo/ } \\
\text { Topografia }\end{array}$ & $\begin{array}{l}\text { Compreender a compreensão } \\
\text { da ciclagem de nutrientes na } \\
\text { Floresta Amazônica e sua im- } \\
\text { portância para a manutenção } \\
\text { da fertilidade do solo e biodi- } \\
\text { versidade da vegetação em } \\
\text { diferentes posições topográfi- } \\
\text { cas. }\end{array}$ & $\begin{array}{l}\text { Aula expositiva dialogada ao longo da tri- } \\
\text { Iha com duração de } 1 \text { hora. } \\
\text { Coleta de solo e liteira sobre o solo com } \\
\text { trado até } 30 \mathrm{~cm} \text { de profundidade confor- } \\
\text { me a delimitação topográfica descrita por } \\
\text { Marques (2016). } \\
\text { A liteira foi separada em: folhas, galhos, } \\
\text { flores/frutos sementes, sendo organizado } \\
\text { em conforme Luizão (2007). }\end{array}$ \\
\hline 3 & $\begin{array}{l}\text { Trilha Terra } \\
\text { Preta de Índio } \\
\text { (TTPI) }\end{array}$ & $\begin{array}{l}\text { Solo } \\
\text { Antrópico }\end{array}$ & $\begin{array}{l}\text { Observar as características } \\
\text { as principais morfológicas dos } \\
\text { solos antrópicos. }\end{array}$ & $\begin{array}{l}\text { Aula expositiva dialogada ao longo da tri- } \\
\text { lha com duração de } 40 \text { minutos. } \\
\text { Abertura de perfil do solo conforme Dos } \\
\text { Santos et al. (2015) }\end{array}$ \\
\hline 4 & $\begin{array}{l}\text { Trilha } \\
\text { Vegetação } \\
\text { de Palmeiras } \\
\text { (TVP) }\end{array}$ & $\begin{array}{l}\text { Tipo de } \\
\text { Vegetação }\end{array}$ & $\begin{array}{l}\text { Demonstrar a importância das } \\
\text { palmeiras para o ecossistema. }\end{array}$ & $\begin{array}{l}\text { Aula expositiva dialogada ao longo da tri- } \\
\text { lha com duração de } 1 \text { hora. } \\
\text { Observação das sementes, folhas, copa } \\
\text { e liteira. }\end{array}$ \\
\hline 5 & $\begin{array}{l}\text { Trilha Rocha, } \\
\text { Solo e Falésia } \\
\text { (TRSF) }\end{array}$ & $\begin{array}{l}\text { Evolução de } \\
\text { Solos }\end{array}$ & $\begin{array}{l}\text { Reconhecer a formação ro- } \\
\text { chosa Alter do Chão, o in- } \\
\text { temperismo e as falésias que } \\
\text { ocorrem no local. }\end{array}$ & $\begin{array}{l}\text { Aula expositiva dialogada ao longo da tri- } \\
\text { lha com duração de } 40 \text { minutos. } \\
\text { Coleta de amostras de rocha, solo e uti- } \\
\text { lização da Carta de Munsell para identifi- } \\
\text { cação da cor do solo (MUNSELL, 1994). }\end{array}$ \\
\hline 6 & $\begin{array}{l}\text { Trilha Encontro } \\
\text { das Águas } \\
\text { (TEA) }\end{array}$ & $\begin{array}{l}\text { Rios da } \\
\text { Amazônia }\end{array}$ & $\begin{array}{l}\text { Observar o encontro das } \\
\text { águas e sua beleza cênica, } \\
\text { ressaltando a importância do } \\
\text { seu tombamento. }\end{array}$ & $\begin{array}{l}\text { Aula expositiva dialogada ao longo da tri- } \\
\text { lha com duração de } 30 \text { minutos. } \\
\text { Observação do Encontro das Águas }\end{array}$ \\
\hline
\end{tabular}

Fonte: Dados da pesquisa (2020). 


\section{Instrumentalização das TI com P|}

Foi realizado uma oficina de sinalização em sala de aula (Figura 2A), onde os alunos destacaram os principais PA que cada trilha visitada possuía quanto aos conteúdos abordados (Figura 2B) para a construção das PI (Figura 2C).

Figura 2: Alunos elaborando um piloto das PI em sala de aula.

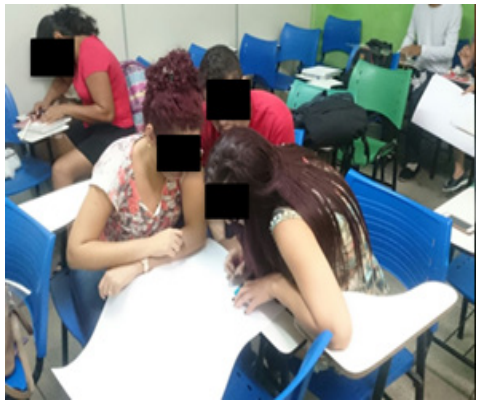

2A

Fonte: Os autores (2020).

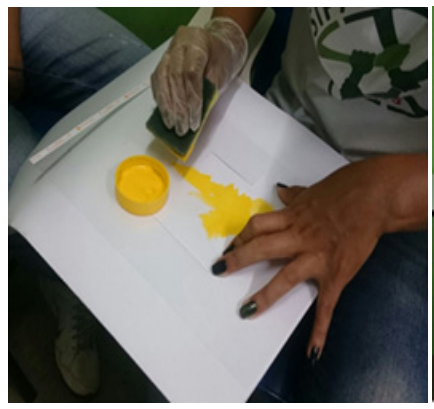

2B

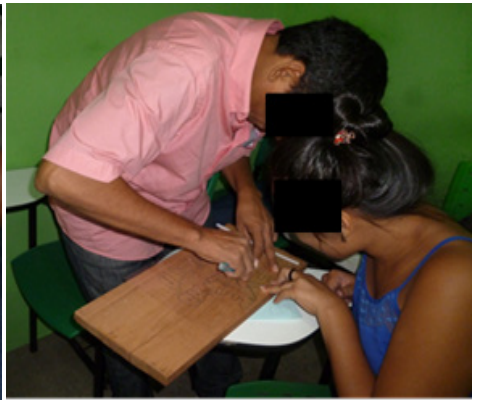

2C

Assim, um piloto das PI foi construído previamente como forma de ser avaliado pelos alunos para que, posteriormente, as PI definitivas fossem construídas e instaladas nas TI. Na avaliação preliminar os alunos responderam a seguinte pergunta: "Você tem alguma sugestão para melhorar as PI"? Participaram desta avaliação, 15 (quinze) alunos. Posteriormente, a instrumentalização definitiva das TI foi realizada por meio da construção de PI de alumínio galvanizado com layout segundo as instruções normativas do ICMbio (2020).

\section{Validação do produto educacional}

A validação final das 6 (seis) PI foi realizada com a participação dos mesmos 15 (quinze) alunos já mencionados, os quais responderam a seguinte pergunta: "qual a importância das PI para a compreensão do conteúdo contido nas TI”?

\section{Verificação da Aprendizagem}

Após a finalização das atividades interventivas em cada trilha, os alunos responderam um questionário com questões semiestruturadas. O intuito era saber se 
as aulas expositivas e o contato dos alunos com o(a) flora, solo e recurso hídrico contribuiu para o processo de ensino e aprendizagem de conteúdos abordados na disciplina EA. Os dados foram transcritos, tabulados, analisados e categorizados, segundo reagrupamento analógico (BARDIN, 2016).

\section{Resultados e Discussão}

\section{Caracterização biofísica das TI}

Na Tabela 1, é possível visualizar as características biofísicas das TI, sendo possível visualizar o comprimento, largura, tempo de caminhada e nível de dificuldade. As TI apresentam as mesmas larguras (1,5 m) com tempos de caminhada de 5 minutos (TER e TEA), 10 minutos (TTPI e TRSF) e 30 minutos (TPT e TVP). As maiores variações foram obtidas no comprimento das trilhas que variam de 109 (TEA) m à 760 (TPT) $\mathrm{m}$ e no nível de dificuldade na TI, que oscilaram entre leve (TER, TRSF e TEA), média (TTPI) e difícil (TPT e TVP).

Tabela 1: Características biofísicas das trilhas.

\begin{tabular}{l|l|l|l|l|l}
\hline$N^{\circ}$ & \multicolumn{1}{|c|}{ Trilha } & Comprimento & Largura & \multicolumn{1}{c}{$\begin{array}{c}\text { Tempo de } \\
\text { caminhada }\end{array}$} & $\begin{array}{c}\text { Nível de } \\
\text { dificuldade }\end{array}$ \\
\hline 1 & Trilha Entrada da Reserva (TER) & $166 \mathrm{~m}$ & $1,5 \mathrm{~m}$ & $\pm 5 \mathrm{~min}$ & Leve \\
\hline 2 & Trilha Perfil Topográfico (TPT) & $760 \mathrm{~m}$ & $1,5 \mathrm{~m}$ & $\pm 30 \mathrm{~min}$ & Difícil \\
\hline 3 & Trilha Terra Preta de Índio (TTPI) & $234 \mathrm{~m}$ & $1,5 \mathrm{~m}$ & $\pm 10 \mathrm{~min}$ & Média \\
\hline 4 & Trilha Vegetação de Palmeiras (TVP) & $367 \mathrm{~m}$ & $1,5 \mathrm{~m}$ & $\pm 30 \mathrm{~min}$ & Difícil \\
\hline 5 & Trilha Rocha, Solo e Falésia (TRSF) & $428 \mathrm{~m}$ & $1,5 \mathrm{~m}$ & $\pm 10 \mathrm{~min}$ & Leve \\
\hline 6 & Trilha Encontro das Águas (TEA) & $109 \mathrm{~m}$ & $1,5 \mathrm{~m}$ & $\pm 5 \mathrm{~min}$ & Leve \\
\hline
\end{tabular}

Fonte: Dados da pesquisa (2020).

Os resultados a seguir serão apresentados a partir da investigação realizada em cada TI localizada na UC, valorizando a IA e seus PA, bem como o contato do aluno com a flora, solo e recurso hídrico com vistas no ensino e aprendizado da disciplina EA.

\section{Trilha Entrada da Reserva (TER)}

Nesta trilha foi necessário destacar o contexto histórico das leis ambientais 6.938 (Política Nacional do Meio Ambiente - PNMA) e 9.985 (Sistema Nacional de Unidades 
de Conservação da Natureza - SNUC) criadas em 1981 e 2000, respectivamente. Além dessas leis estarem incluídas no conteúdo de EA, esta abordagem inicial foi necessária e pertinente como forma de exemplificar a importância da utilização desta trilha como exemplo prático dos princípios, objetivos e instrumentos da PNMA, bem como dos critérios, normas para a criação, classificação implantação e gestão das unidades de conservação. Foi possível abordar as Leis, pois os seus conteúdos foram facilmente observados nas TI em termos de aplicabilidade, valorizando o contato do aluno com a flora, fauna, solo e recursos hídricos, mais difícil de serem compreendidos em uma aula tradicional em sala. No mesmo sentido, como esta UC foi explorada pelo desmatamento, mas, atualmente, está em processo de recuperação por meio de reflorestamento, os alunos visualizaram essas características (Figura 1).

Figura 1: Alunos na TER observando as características da TI.

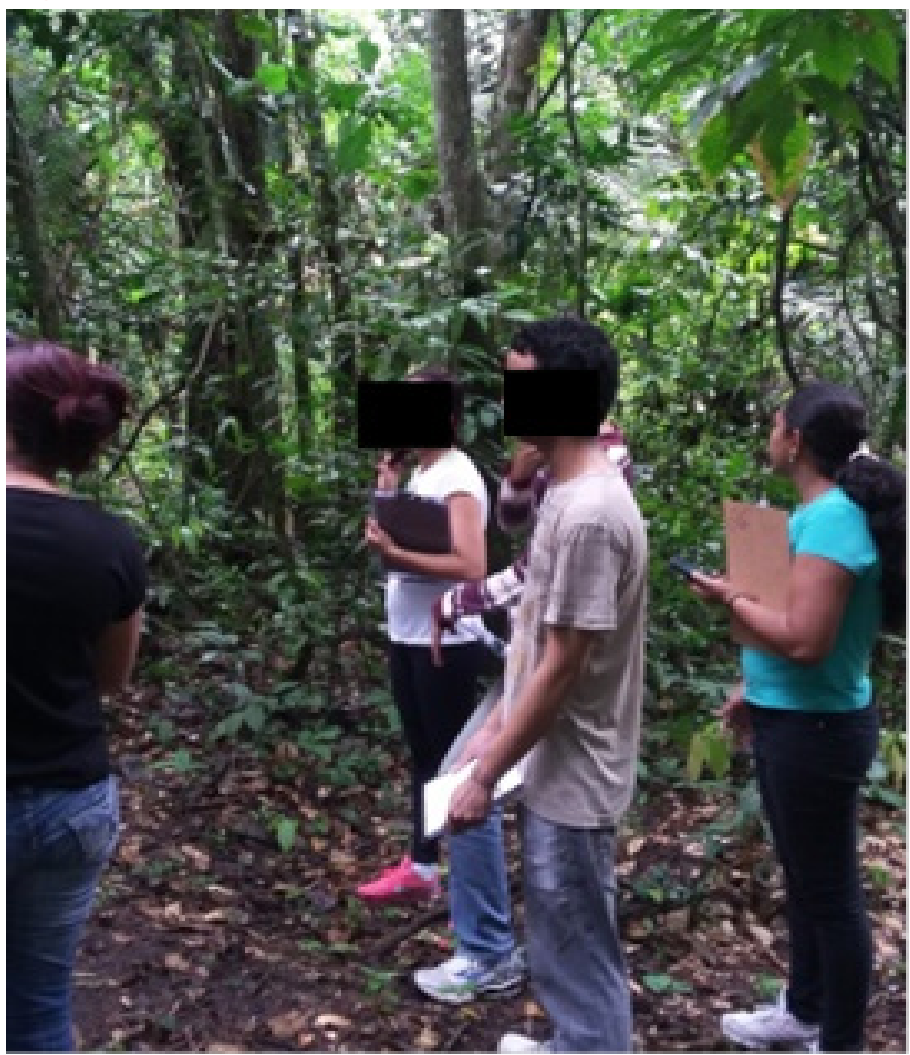

Fonte: Os autores (2020). 
Na Tabela 2 observamos as respostas dos alunos durante a aula dialogada realizada na TER. Preliminarmente, as 3 (três) primeiras questões objetivavam verificar o grau de conhecimento dos alunos quanto aos conteúdos abordados. Surpreendentemente, $64 \%$ dos alunos disseram já conhecer alguma lei ambiental, bem como 75\% narraram terem usado alguma lei em atividades acadêmicas (Questão 1) e foram unanimes em destacar (100\%) ser importante saber sobre as leis que norteiam o direito ambiental (Questão 2). Muitas vezes esse conhecimento é obtido por meio da televisão, rádio, jornal impresso e internet, que noticiam as consequências das mudanças em diversas partes do Mundo (FREITAS; MARQUES; SOUZA, 2020). O próprio curso de graduação oferece possibilidades via projetos de PIBIC e extensão possibilitando acesso a um conhecimento prévio sobre temáticas ambientais (Questão 3), o que facilita ensinar EA usando TI em UC. Os alunos demonstraram grande interesse pela temática tratada, mesmo porque já traziam consigo conhecimento básico e, principalmente, entusiasmo nas discussões demonstrando grande facilidade na compreensão dos princípios, objetivos, instrumentos das Leis Ambientais e classificação das UC.

Sobral (2014), que também aborda essa questão, entende que:

Estudantes universitários nos dias atuais fazem parte de um grupo social que tem a sua disposição uma grande cobertura de informações a respeito de questões ambientais, principalmente pela comunicação em massa, mais ampla que a geração anterior (SOBRAL, 2014, p.22).

No tocante a importância em saber sobre as leis (Questão 2), observamos a responsabilidade e consciência que os alunos terão no futuro em proteger o ambiente como profissionais por meio dos relatos "sim, pois seremos profissionais de biologia" (A2, A5, A9, A10, A12 e A13); "muito importante, pois faz parte da área em que eu atuo" (A5, A8, A11, A14 e A15); "se torna importante, pois podemos desenvolver atividades profissionais que dependem do que aprendemos na faculdade” (A1, A3, A4, A6 e A7). Recentemente, Freitas, Marques e Souza (2020) também encontraram resultados semelhantes em pesquisa realizada em UC no mesmo bioma, conseguindo demonstrar conceitos fundamentais sobre Mudanças Climáticas Globais a partir dos componentes da campina, campinarana e floresta primária, bem como abordar a importância da preservação desses, viabilizando o processo de ensino e aprendizagem sobre essa temática no contexto de ecossistemas amazônicos. 
Tabela 2: Respostas dos alunos durante a aula dialogada realizada na TER.

\begin{tabular}{|c|c|c|c|}
\hline Questões & Sim & Não & Respostas categorizadas \\
\hline $\begin{array}{l}\text { 1) Você conhecia sobre } \\
\text { alguma lei ambiental } \\
\text { antes dessa aula? }\end{array}$ & $64 \%$ & $36 \%$ & $\begin{array}{l}\text { A5: "A lei sobre Educação Ambiental - Lei 9.795"; } \\
\text { A8: "Lei PNMA - os CONAMAS referentes a agua"; } \\
\text { A11: "Lei de crimes sobre o ambiente". } \\
\text { A9, A2, A3, A6, A9, A10 e A12: "Sim" } \\
\text { A1, A13, A14 e A15: "não muito"; A3 e A7: “não". }\end{array}$ \\
\hline $\begin{array}{l}\text { 2) Você acha importan- } \\
\text { te saber sobre as leis } \\
\text { que norteiam o direito } \\
\text { ambiental? }\end{array}$ & $100 \%$ & - & $\begin{array}{l}\text { A2, A5, A9, A10, A12 e A13: "sim, pois seremos profissionais de } \\
\text { biologia"; } \\
\text { A5, A8, A11, A14 e A15: "muito importante pois faz parte da área } \\
\text { em que eu atuo"; } \\
\text { A1, A3, A4, A6 e A7: "Se torna importante, pois podemos desenvol- } \\
\text { ver atividades profissionais que dependem do que aprendemos na } \\
\text { faculdade". }\end{array}$ \\
\hline $\begin{array}{l}\text { 3) Já fez uso de alguma } \\
\text { lei em atividades aca- } \\
\text { dêmicas? }\end{array}$ & $75 \%$ & $25 \%$ & $\begin{array}{l}\text { A2, A9, A10, A12, A13 e A14: "Nas atividades de extensão"; } \\
\text { A5, A7, A8, A11 e A15: "Na iniciação cientifica (PIBIC)"; } \\
\text { A1, A3, A4, A6: "não". }\end{array}$ \\
\hline $\begin{array}{l}\text { 4) De que forma elas } \\
\text { podem ser visualiza- } \\
\text { das de forma prática? }\end{array}$ & $\begin{array}{l}\text { Não se } \\
\text { aplica }\end{array}$ & $\begin{array}{l}\text { Não se } \\
\text { aplica }\end{array}$ & $\begin{array}{l}\text { A3, A7 e A11: "em empresas que usam essas leis"; } \\
\text { A1, A2, A4, A5, A6, A8, A9, A10, A12 A13, A14 e A15: "Em aula prá- } \\
\text { tica onde podemos ver como são usadas e respeitadas". }\end{array}$ \\
\hline $\begin{array}{l}\text { 5) Após a aula na TER, } \\
\text { ficaram claros os ob- } \\
\text { jetivos e instrumentos } \\
\text { da Lei } n^{\circ} 6.938 \text { que } \\
\text { estabelece a PNM? }\end{array}$ & $82 \%$ & $18 \%$ & $\begin{array}{l}\text { A1 e A15: "Não"; } \\
\text { A2, A3, A4, A5, A6, A7, A8, A9, A10, A11, A12, A13 e A14 - "Sim". }\end{array}$ \\
\hline $\begin{array}{l}\text { 6) Após a aula, você } \\
\text { sabe identificar quais } \\
\text { as categorias de Uni- } \\
\text { dades de Conserva- } \\
\text { ção? }\end{array}$ & $100 \%$ & - & $\begin{array}{l}\text { A1, A2, A5, A8 e A11: "existem dois tipos as de uso integral e as de } \\
\text { uso sustentável"; } \\
\text { A3, A9, A13 e A14 "proteção integral e uso sustentável"; } \\
\text { A4, A6, A7, A10, A12 e A15: "A lei } 9.985 \text { separa em duas classes: } \\
\text { as de proteção integral e as de uso sustentável, a RPPN é uso } \\
\text { sustentável por exemplo". }\end{array}$ \\
\hline
\end{tabular}

Fonte: Dados da pesquisa (2020).

\section{Trilha Perfil Topográfico (TPT)}

Esta trilha foi uma oportunidade única para os alunos conhecerem as variações no relevo/topografia no bioma amazônico, compreendendo a importância da ciclagem de nutrientes na Floresta Amazônica e sua importância para a manutenção da fertilidade do solo e biodiversidade da vegetação em diferentes posições topográficas (platô, vertente e baixio). Marques et al. (2016) delimita para este bioma a topografia em platô (90 à $120 \mathrm{~m}$ de altitude), vertente (75 à $90 \mathrm{~m}$ de altitude) e baixio (50 à 75 $\mathrm{m}$ de altitude). Esta temática é bem característica do Bioma Amazônia e proporcionou aos alunos um conhecimento sobre a dinâmica da ciclagem de nutrientes. 
Assim, a aula foi conduzida explanando sobre as diferenças nas diferentes posições topográficas. Foi explicado e visualizado pelos alunos que no platô, vertente e baixo as características do (a) solo, vegetação e entrada de luz sofrem variações em decorrência da posição topográfica (Tabela 3). Para elucidar melhor as diferenças abordadas podemos visualizar na Tabela 3 os resultados das análises realizadas a partir das amostras coletadas pelos alunos sob a orientação do professor.

Tabela 3: Resultados das análises realizadas na TPT.

\begin{tabular}{l|l|l|l}
\hline \multicolumn{1}{c|}{ Posição } & \multicolumn{1}{c|}{ Massa de Liteira $\left(\mathrm{kg} \mathrm{ha}^{-1}\right)$} & Classe de Solo & \multicolumn{1}{c}{ Entrada de Luz } \\
\hline Platô & 49,8 & Latossolo & Baixa \\
Vertente & 45,5 & Argissolo & Moderada \\
Baixio & 40,0 & Espodossolo & Alta \\
\hline
\end{tabular}

Fonte: Dados da pesquisa (2020).

Os resultados apresentados na Tabela 3 estão de acordo com outros estudos neste bioma quanto as variações na massa de liteira produzida (MONTEIRO, 2005), classe de solo (MARQUES et al., 2016) e entrada de luz (MARQUES; OLIVEIRA; PAES, 2019) nas posições topográficas estudadas. Observamos que existem diferenças na massa de liteira, na classe de solo e na entrada de luz, diretamente influenciados pela posição topográfica.

O conteúdo sobre relevo/topografia é característico de cada bioma e o professor necessita buscar alternativas pedagógicas como as aqui desenvolvidas como forma de promover o ensino da temática e aprendizado dos alunos. É impossível reconhecer relevo/topografia sem vivenciar alguma atividade prática, seja ela no campo ou por meio de uma dinâmica pedagógica para tal fim. A estratégia pedagógica desenvolvida na TPT é uma alternativa viável para que professores que ministram esta temática nos cursos de EA possam desenvolver.

A potencialização de atividades investigadoras que torne o aluno protagonista da ação, além de promover a educação cientifica efetiva contextualizada com a realidade regional e global, permite uma melhor abordagem interativa entre aluno e professor (MARQUES; OLIVEIRA; PAES, 2019).

\section{Trilha Terra Preta de Índio (TTPI)}

Na TTPI foi abordado uma temática extremamente regional abordada na EA que é a presença dos solos antrópicos na Amazônia. Somente 9\% dos alunos relataram 
já conhecer o significado dessa classe de solo. A abertura do perfil de solo foi o PA de suma importância para exemplificar suas principais características (Figura 2).

Figura 2: Perfil de solo antrópico aberto para conduzir a aula na TTPI.

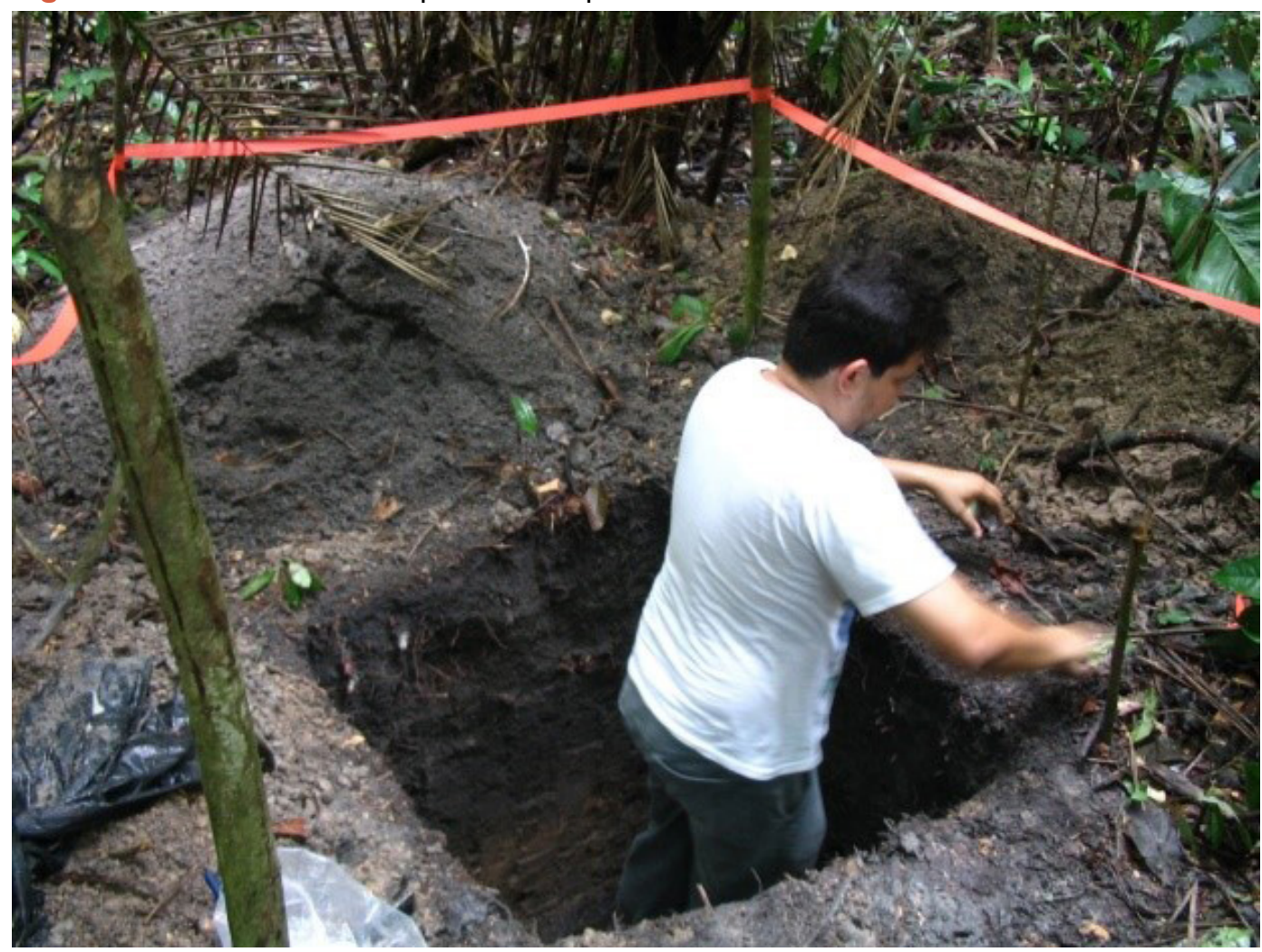

Fonte: Os autores (2020).

No perfil, os alunos foram estimulados a observar a cor do solo. A grande maioria dos alunos relatou não conhecer essa característica (98\%). O solo tinha a cor marrom escuro (Figura 2). Os alunos também observaram que as plantas ao redor eram mais frondosas devido à alta fertilidade desses solos proporcionada pela maior presença de matéria orgânica do solo (MOS). Botelho e Marques (2020) destacaram que a MOS é maior nos solos antrópicos quando comparado com Latossolo. A presença desses solos contribuiu ecologicamente com a fauna e flora do local, pois disponibiliza nutrientes em abundância. Portanto, a TTPI apresenta um grande potencial ecológico de ensino em termos de sustentabilidade ambiental, interações ecológicas e disponibilidade de nutrientes para serem abordados com alunos na disciplina EA. 
Trilha Vegetação de Palmeiras (TVP)

AIA na TVP demonstrou para os alunos a importância da vegetação de palmeiras para o ecossistema a partir da observação da trilha, destacando as plantas existentes e características das suas sementes, folhas, copa e liteira sobre o solo (Figura 3). Perguntamos aos alunos o que percebem ao olhar a vegetação predominante nesta trilha? Os alunos responderam "tem muitas palmeiras e a trilha é plana, diferente da outra que visitamos" (A4, A7, A13 e A14); "essa trilha possui um igarapé” (A8 e A15); "tem mais frutos no chão" (A3 e A5); "muitas folhas grandes sobre o chão" (A1, A2, A6 e A9); "é úmido e não tem luz" (A10, A11 e A12).

Os relatos dos alunos caracterizam muito bem a TVP, pois é afetada ocasionalmente pela subida do nível do rio. Além disso, fica parcialmente alagada se a cheia for considerável. A vegetação é adaptada a áreas alagadiças, o que faz com que sobreviva mesmo com o excesso de água em período chuvoso. A percepção dos alunos quanto à altura das plantas, frutos, entrada de luz e umidade no ambiente foi percebida pelo olhar, olfato e tato, estimulando esses sentidos. A utilização das trilhas permite também a construção de conhecimentos científicos significativos, estimula ganhos cognitivos e relacionados às dimensões sociais e afetivas, melhoria na autoestima, no senso de responsabilidade individual e coletiva e na manutenção da cidadania (COSTA et al., 2014).

Figura 3: Fruto de buriti (A), Planta de buriti (Mauritia flexuosa) (B) e Plantas de açaizeiro (Euterpe oleracea) (C).

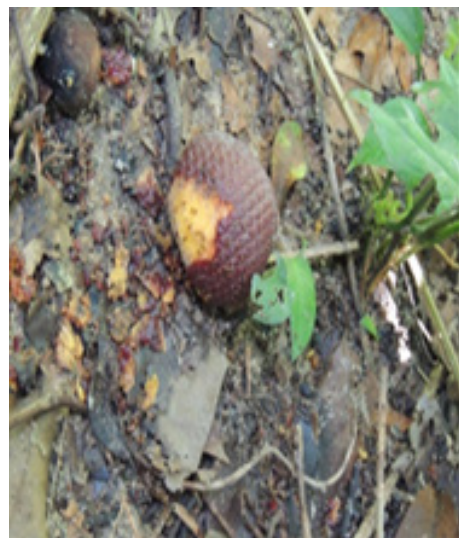

A

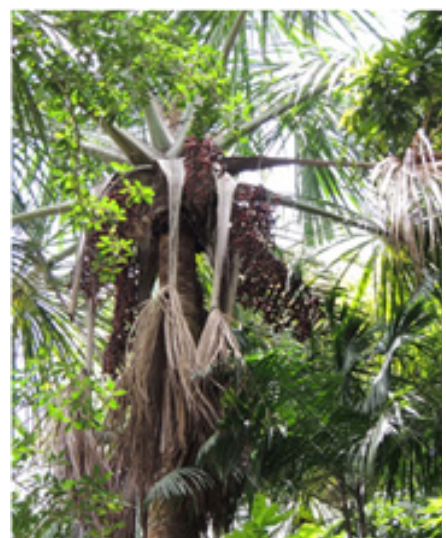

B

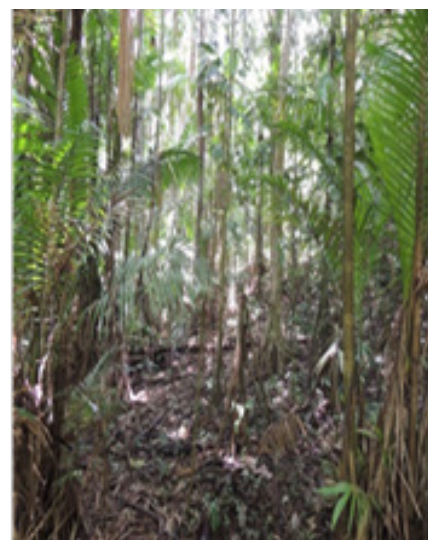

C

Fonte: Os autores (2020). 
A Tabela 4 apresenta as respostas dos alunos quanto a questões mais específicas sobre a TVP. Podemos observar que os alunos conseguiam identificar as palmeiras como um tipo de vegetação predominante.

Tabela 4: Respostas dos alunos na TVP.

\begin{tabular}{|c|c|}
\hline Questões & Respostas categorizadas \\
\hline $\begin{array}{l}\text { 1) Quais os tipos } \\
\text { de espécies e } \\
\text { ou vegetação } \\
\text { predominante na } \\
\text { área? }\end{array}$ & $\begin{array}{l}\text { A1, A2, A3, A4, A6, A8, A9, A10, A11, A12, A13 e A14: "palmeiras"; } \\
\text { A5: "Palmeiras, capim, diversas árvores"; } \\
\text { A15: "As florestas de baixio parecem ser um ambiente chave para o estabelecimento } \\
\text { de espécies de terra firme nas áreas inundáveis, possibilitando o desenvolvimento de } \\
\text { adaptações a situações episodicamente hipóscicas, por ocorrência episódicas das } \\
\text { enchentes"; } \\
\text { A7: "Palmeiras nas trilhas e gramíneas em áreas abertas. As palmeiras que foram } \\
\text { observadas em grande maioria foram açaizeiros, buritizeiros, tucumanzeiros". }\end{array}$ \\
\hline $\begin{array}{l}\text { 2) Essa vegetação } \\
\text { é considerada } \\
\text { hiperdominante } \\
\text { neste ambiente? } \\
\text { Explique }\end{array}$ & $\begin{array}{l}\text { A1, A2, A6, A7 e A14: "Sim, pois suas estruturas adaptativas evoluíram para que se } \\
\text { adequasse ao local de solo arenoso, mas com muita liteira na superfície"; } \\
\text { A5, A8, A9, A10 e A11: "Sim, pois ela inibi o crescimento de espécies que não sejam } \\
\text { da mesma família"; } \\
\text { A12: "Sim na terra firme o baixio é o ambiente que mais se aproxima das condições } \\
\text { encontradas em florestas inundáveis, com espécies arbóreas adaptadas as imersões } \\
\text { episódicos pelo nível das águas dos igarapés. } \\
\text { A13 e A15 "As palmeiras são típicas desse ambiente úmido"; } \\
\text { A7: "Sim esse tipo de vegetação (Palmeiras) são árvores que medem em média } 20 \text { a } \\
35 \text { m, por serem altas e muito próximas umas das outras dificultam a propagação de } \\
\text { sementes de outras espécies". }\end{array}$ \\
\hline $\begin{array}{l}\text { 3) Quais as carac- } \\
\text { terísticas do solo } \\
\text { sob palmeiras? }\end{array}$ & $\begin{array}{l}\text { A2 e A14: "O solo apresenta grande quantidade de liteira, o que torna o solo mais } \\
\text { úmido e propenso à vegetação de palmeiras mesmo sendo arenoso"; } \\
\text { A5: "A comunidade de palmeiras se distribui em três zonas: solos bem drenados (pla- } \\
\text { tô, topo, vertente), solos pobremente drenados (zona de transição) e solos sazonal- } \\
\text { mente inundados (igarapés)"; } \\
\text { A7: "Solo arenoso, com espessa camada de liteira cerca de 1,50 m, úmido"; } \\
\text { A8: "Um solo com uma textura mais úmida, rico em nutrientes, uma coloração escura, } \\
\text { sendo possível encontrar uma quantidade de matéria orgânica em decomposição, que } \\
\text { ajuda na proteção e enriquecimento do solo"; } \\
\text { A1, A3 e A9: "Solo com mais umidade, bastante nutriente, rico em liteira"; } \\
\text { A4, A6, A9, A10, A11 e A13: "Solo rico em matéria orgânica, fértil"; } \\
\text { A15: "Solo fértil, drenável, úmido enriquecido com matéria orgânica"; } \\
\text { A12: "A liteira é bastante espessa com a presença de muitas folhas e sementes caídas } \\
\text { das palmeiras, isso tornava o solo baste instável para caminhar. Observa-se também } \\
\text { a presença de artrópodes como aranhas". }\end{array}$ \\
\hline
\end{tabular}

Fonte: Dados da pesquisa (2020).

Definidamente por meio da Questão 1, observamos que os alunos conseguiram identificar as principais características das palmeiras, pois as reconheceram com facilidade ao longo da TVP (A1, A2, A3, A4, A5, A6, A8, A9, A10, A11, A12, A13 e 
A14), bem como a hiperdominância que exercem sobre o local onde estão inseridas (Questão 2). As respostas são satisfatórias e estão de acordo com o abordado ao longo da aula dialogada na trilha, pois destacam a hiperdominância da vegetação de palmeiras e cada aluno enfatiza um aspecto que explica esta característica como pode ser visto nas respostas dos alunos A5, A8, A9, A10, A11: "[Sim, pois ela inibi o crescimento........]” e A7: [“Sim esse tipo de vegetação (Palmeiras) são árvores...........]”. Ribeiro, Araújo e Santana (2007) relatam que as palmeiras encontradas na Amazônia, como Buriti, estão restritas ao Baixio. Para a dinâmica ecológica da Amazônia, o solo de palmeiras é muito importante e é responsável pela concentração de palmeiras comestíveis, frutíferas, com valor econômico e que entender essa dinâmica é de extrema relevância para os alunos. Nesses ambientes são comuns solos arenosos, justamente o que foi compreendido pelos alunos e transcrito nas respostas da Questão 3, sendo visualizado nas repostas dos alunos A1, A3 e A9: "Solo com mais umidade" e A12: ["A liteira é bastante espessa com a........]. Resultados sobre o uso dos solos e sobre a vegetação como método didático-pedagógico foi encontrado também por outros autores (OLIVEIRA; MARQUES, 2017).

\section{Trilha Rocha, Solo e Falésia (TRSF)}

A IA na TRSF promoveu o ensino e aprendizado do reconhecimento da evolução de solo por meio de falésia nas margens do Rio Negro e a formação rochosa Alter do Chão característica no local. Assim, coletamos amostras de rocha e solo ao longo da TRSF para que os alunos as texturassem (esfregar o solos entre os dedos) e utilizassem um torrão (resultado de partículas primárias ou secundárias do solo) como amostra representativa do solo para caracterizar a sua cor por meio da Carta de Munsell (Figura 4). 
Figura 4: Alunos na TRSF observando a formação Alter do Chão $(A)$, coleta de amostras de rocha $(B)$, coleta de amostras de solo no sopé da Falésia (C) e Manuseio da Carta de Munsell no campo para identificação da cor do solo (D).

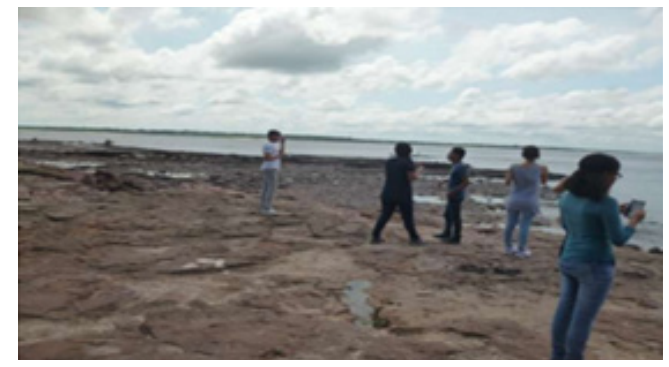

A

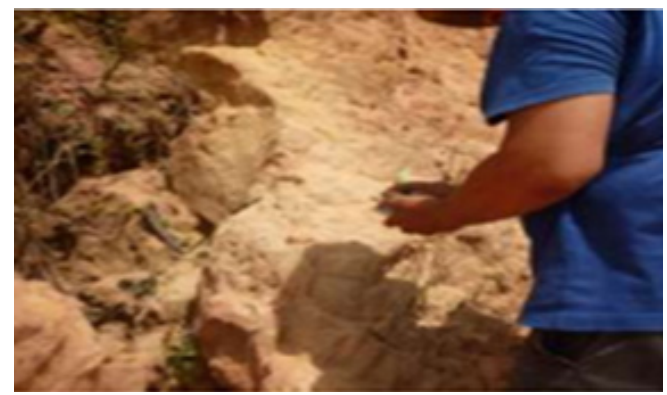

C

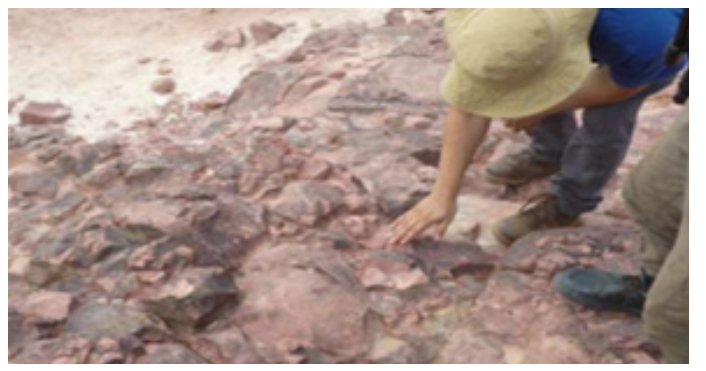

B

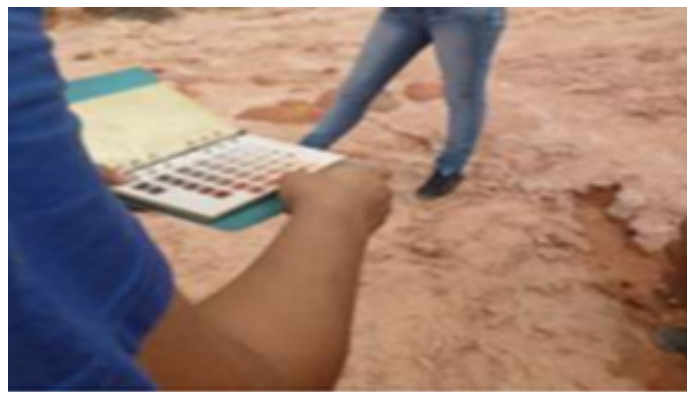

D

Fonte: Os autores (2020).

Assim como nas outras trilhas, os alunos foram estimulados a observá-la e ao adentrarem responderam "o que chama mais sua atenção"? O relato dos alunos foi "o solo tem cor característica dos solos da Amazônia" (A1 e A9), "não sabia que tinha essa praia, parece com outras praias no rio, mas diferente por conter essa formação rochosa" (A14), "A rocha está exposta com a baixa do rio" (A4, A6 e A7), "Os solos têm diferentes cores" (A3, A8, A10, A11 e A12), "A rocha está abaixo do solo" (A5, A13 e A15). As respostas representam a riqueza da TRSF, com vários PA para serem utilizadas nas aulas de EA. A localização desta trilha foi influenciada diretamente pela subida e descida das águas do rio. Como estava situada na margem do Rio Negro, é afetada todos os anos pela subida e descida do rio, o que justifica as respostas quanto dos alunos A4, A6, A7 e A14. Na época de seca, é possível caminhar sobre a rocha (Figura 4A) e visualizar a formação rochosa (Figura 4B). As cores do solo também foram bem evidenciadas nas falas dos alunos (A1, A3, A8, A9, A10, A11 e A12). Portanto, o contato do aluno com a rocha, solo e falésia 
foram extremamente importantes para a compreensão desse conteúdo. Botelho e Marques (2019) afirmam que a prática de campo de caráter investigativo, exploratório e interdisciplinar possibilita o ensino de origem, formação, ocupação, erosão e preservação do solo de forma prática, permitindo aos estudantes compreender os processos, transformações e interações que regem essas temáticas, impossíveis de serem compreendidas apenas em sala de aula, propiciando uma experiência capaz de desvendar o ambiente no qual os alunos estão inseridos. Botelho e Marques (2020) também observaram o despertar nos alunos de atitudes, habilidades, posicionamentos e competências quanto à preservação e conservação do solo, bem como frente aos processos, dinâmicas e transformações observadas ao longo do desenvolvimento de atividades práticas sobre solos em UC. Os mesmos autores ainda salientam ser necessário repensar a prática pedagógica no sentido de problematizar o ensino do solo no campo, a fim de estabelecer relações necessárias com o contexto regional favorecendo valores sociais e ambientais.

\section{Trilha Encontro das Águas (TEA)}

A IA na TEA discutiu com os alunos o conteúdo sobre Rios da Amazônia, a partir da observação do encontro das águas e sua beleza cênica, ressaltando a importância do seu tombamento. Dentre os PA da TEA destacamos à vista panorâmica do encontro dos Rios Negro e Solimões, vulgarmente conhecido como "Encontro das Águas" (Figura 5).

Figura 5: Visão panorâmica do encontro das águas $(A)$ sendo observado pelos alunos sentados durante a aula (B).

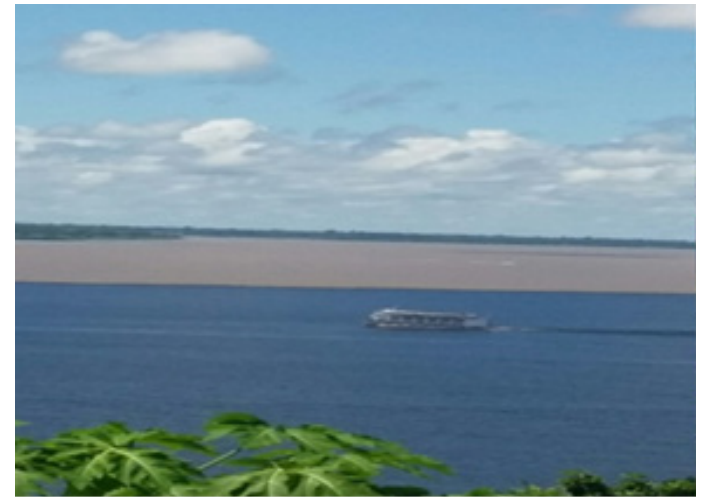

A

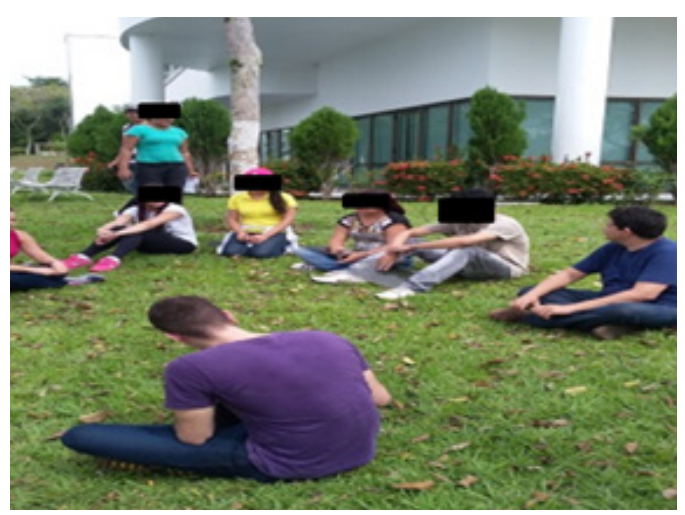

B

Fonte: Os autores (2020). 
A IA da TEA foi realizada a partir do histórico do local. Foi dito que aquele ambiente recentemente tinha sido alvo de especulações para a construção de um novo porto para a cidade de Manaus e de uma área de lazer, fato este uma realidade local. Nesse aspecto, foi perguntado aos alunos se os mesmos concordavam com esse tipo de obras. Por unanimidade, relataram que obras desse tipo poderiam trazer degradação ao ambiente. Esses fatos foram ponderados para estimular a percepção dos alunos sobre possíveis consequências para a conservação do ambiente, o que resultou em uma discussão e apropriação de conceitos na TEA. Para Santos, Flores e Zanin (2011), a IA é uma oportunidade de desenvolvimento humano que estimula a capacidade investigadora, levando o homem a repensar seu modo de ver e sentir o planeta como um todo, a partir da leitura e da percepção da realidade ambiental. Dessa forma, a natureza se firma como ferramenta facilitadora do aprendizado; concebe-se a educação biológica como estratégia para a proteção dos recursos naturais.

As UC têm por objetivo a conservação da biodiversidade, a preservação de locais de beleza cênica e dos ambientes históricos. Murta e Goodey (2005) falam que interpretar não é apenas informar sobre algo, mas é um ato de comunicação. Amaral, Carvalho e Coutinho (2020), em atividade multidisciplinar desenvolvida em TI, destacaram que proporcionou aos discentes atividade física, ressignificação de conceitos biológicos relacionados ao ensino de Botânica, auxílio mútuo, aprendizagem, integração com a natureza.

No âmbito da ecologia, de uma forma geral, o Bioma amazônico é tão amplo como complexo. Existe a necessidade de se estudar as características amazônicas mais afundo com uma disciplina específica para tal, como EA. Como relatado por Ab’Saber (2002), a Amazônia brasileira possui interesse científico e didático e complementa dizendo que há noção erronia de que o ecossistema é formado apenas por floresta:

O fato de a região ter sido apresentada sempre como o império das florestas equatoriais, de disposição zonal, acarretou distorções sérias nos estudos dos ecossistemas regionais. É certo que, em termos do espaço total amazônico, predominam esmagadoramente os ecossistemas de florestas dotadas de alta biodiversidade. Entretanto, se levarmos em conta o conceito original de ecossistema, independentemente das disparidades espaciais de sua ocorrência, chegaremos a um número bem maior de padrões ecológicos locais ou sub-regionais (AB'SABER, 2002, p.7). 
Nessa perspectiva, a educação é a forma mais eficaz para alcançar uma gestão de recursos ambientais equilibrada, pois possui a capacidade de desenvolver ações educativas numa perspectiva de construir novas olhares, valores educacionais e éticos nos alunos e na sociedade (LIMA; MARQUES, 2019).

\section{Produto Educacional}

Na Tabela 5 é possível observar os relatos das sugestões dos alunos quanto à avaliação preliminar do piloto das PI construído.

Tabela 5: Relatos das sugestões dos alunos quanto à avaliação preliminar do piloto das PI construído.

\begin{tabular}{|c|c|}
\hline Alunos & "Você tem alguma sugestão para melhorar as Pl"? \\
\hline A1 & As placas poderiam ser posicionadas para uma melhor visualização de grandes grupos. \\
\hline A2 & $\begin{array}{l}\text { Usar sempre um tamanho de fonte que seja agradável aos olhos quando forem lidas além } \\
\text { de posicioná-las a uma altura adequada. }\end{array}$ \\
\hline A3 & As placas poderiam ter mais informações sobre a vegetação a ser encontrada na trilha. \\
\hline A4 & Identificar as espécies no decorrer da trilha indicando sua importância. \\
\hline A5 & $\begin{array}{l}\text { Falar sobre a qualidade das espécies de fauna e flora amazônicas e mostrar as interações } \\
\text { que existem das espécies com outras espécies no âmbito ecológico. }\end{array}$ \\
\hline A6 & $\begin{array}{l}\text { As placas são bem elaboradas e contém informações relevantes que contribuem para uma } \\
\text { melhor experiência na trilha. }\end{array}$ \\
\hline A7 & $\begin{array}{l}\text { Talvez visando questão da educação inclusiva as placas poderiam ter algo de Braille pelo } \\
\text { menos as partes principais como tipo de vegetação encontrada, os números de emergência } \\
\text { as atividades da trilha isto é válido para libras. }\end{array}$ \\
\hline A8 & É uma su \\
\hline A9 & As placas poderiam ser posicionadas para uma melhor visualização de grandes grupos. \\
\hline A10 & $\begin{array}{l}\text { Sim, nem tudo consta nas placas porque a biodiversidade da unidade é grande, mas os } \\
\text { pontos principais da trilha estão nas placas. }\end{array}$ \\
\hline A11 & $\begin{array}{l}\text { Estender o público-alvo e considerar a educação inclusiva (através do uso de libras nas } \\
\text { placas, por exemplo), seria uma opção válida. }\end{array}$ \\
\hline A12 & $\begin{array}{l}\text { Acredito que mostrar mais nas placas a biodiversidade dos animais na mesma reserva seria } \\
\text { interessante também. Apesar de já conter, mas em menor foco. }\end{array}$ \\
\hline A13 & $\begin{array}{l}\text { Poderia haver descrição da vegetação predominante em todo o tipo de relevo e sua impor- } \\
\text { tância. }\end{array}$ \\
\hline A14 & Identificar as espécies no decorrer da trilha indicando sua importância. \\
\hline A15 & Falar sobre as espécies de fauna e flora amazônicas. \\
\hline
\end{tabular}

Fonte: Dados da pesquisa (2020). 
A maioria das sugestões foi considerada para a construção final das PI como foi o caso das sugestões dos alunos no tocante ao posicionamento das placas (A1 e A9), fonte das letras adequadas (A2 e A8) e as espécies existentes no decorrer da trilha (A4 e A14). Entretanto, algumas sugestões foram parcialmente atendidas, pois requeriam "[...mais informações sobre a vegetação.....]", "[.....falar sobre a qualidade das espécies da fauna e flora......]", "[......descrição da vegetação.....]" e "[falar sobre as......]", respectivamente dos alunos A3, A5, A13 e A15. As PI devem conter os pontos de maior atratividade percebido e visualizado na TI (BARRETO; MARQUES; AZEVEDO, 2019). Na realidade as placas apresentam a quantidade necessária de informações contidas nas TI, fato este, constatado pelos alunos A10 e A12. Portanto, todas as sugestões culminaram para a obtenção de PI bem elaboradas e adequadas para o ensino de EA (A6). Para o momento, não foi possível atender as sugestões dos alunos A7 e A11 devido os recursos financeiros para a construção das PI não serem suficientes para tal adaptação, mas concordamos que são extremamente importantes e necessários a inserção da linguagem de sinais. Atualmente, estamos buscando recursos junto a agencias financiadoras para promover tal adequação. Além disso, a continuidade dos estudos nas PI construídas e instaladas podem promover o aprimoramento do que já foi desenvolvido com vistas numa melhor interação dos conteúdos ecológicos contidos na disciplina EA com os PA existentes nas TI.

Assim, apresentamos as 6 (seis) PI, elaboradas pelos alunos e professor, fincadas permanentemente na entrada de cada TI estudada como produto educacional desta pesquisa (Figura 6). Relembrando que esta instrumentalização foi realizada para promover melhor compreensão dos alunos sobre os conteúdos relacionados à EA (Quadro 1). Por outro lado, as PI auxiliarão a quem visitar a UC, contribuindo para o processo de ensino e aprendizagem da sociedade como um todo. 
Figura 6: PI fincadas na entrada de cada TI. A) TER; B) TPT; C) TTPI; D) TVP; E) TRSF; F) TEA.

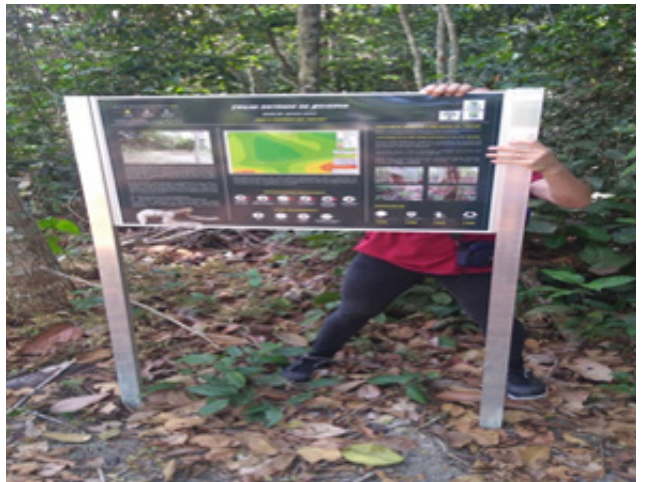

A)

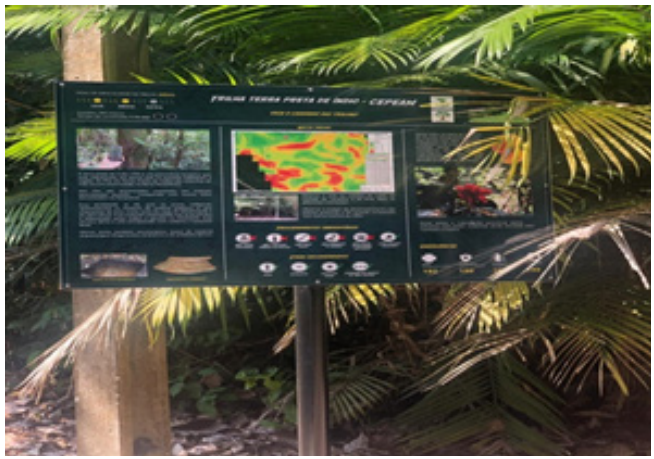

C)

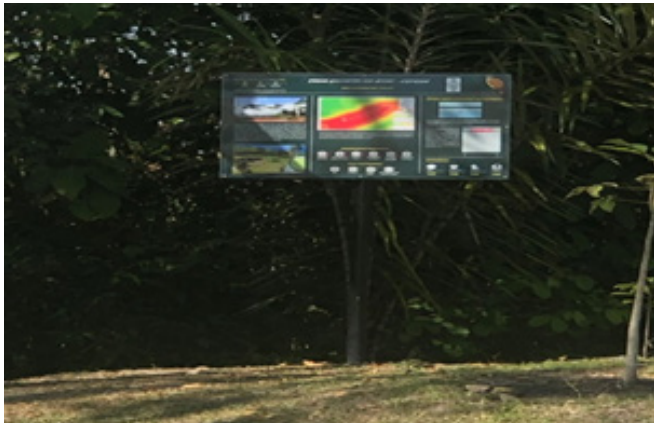

E)

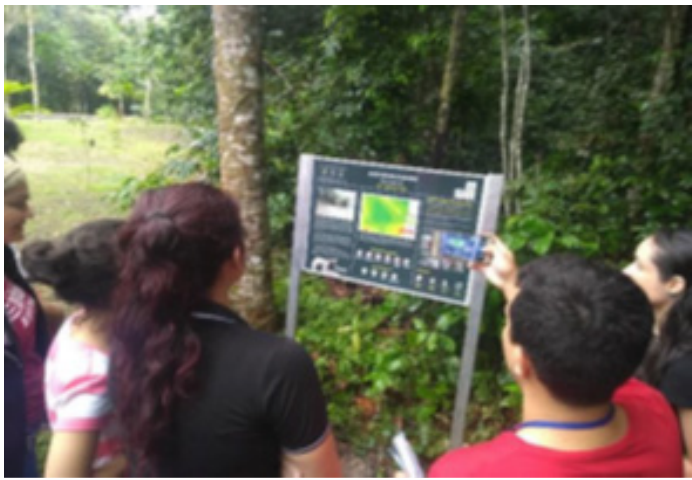

B)

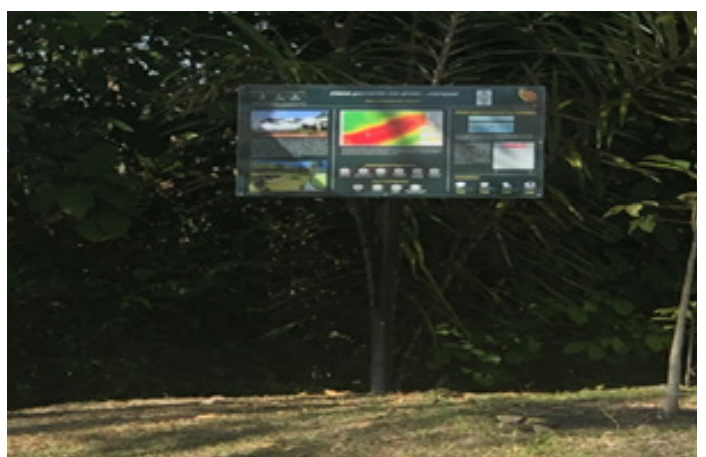

D)

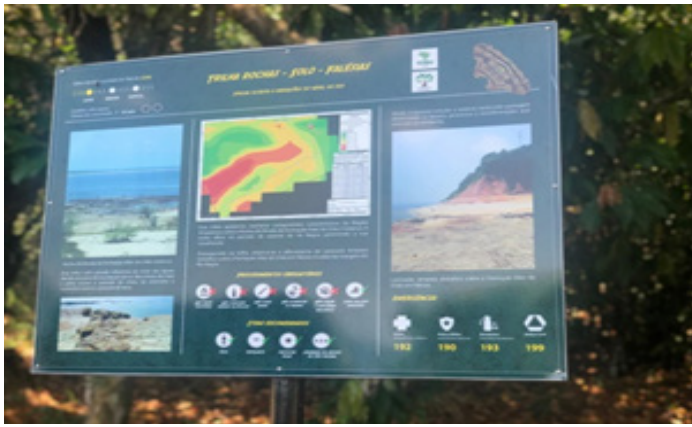

F)

Fonte: Produtos da pesquisa (2020). 
Na validação das PI percebemos o quanto foi importante o feedback dos alunos para o desenvolvimento deste produto educacional, pois proporcionou com que avaliássemos cada etapa e produzíssemos o produto com base nas contribuições dos mesmos. O próprio layout das PI obedeceu às instruções normativas do ICMbio (2020) e as sugestões dos alunos. As PI com informações quanto o grau de dificuldade das TI (leve, médio e difícil); comprimento das TI (m) e tempo de caminhada (localizados do lado superior à esquerda); à esquerda e à direita no meio estão os conteúdos ecológicos específicos para cada TI; no centro está o mapa altimétrico demonstrando o caminho a ser percorrido; ainda no centro, mas na base da PI, estão descritos os procedimentos obrigatórios ao visitar as TI tais como: não fazer fogueiras, não consumir bebidas alcoólicas, não levar armas, não alimentar os animais, não caçar e explorar recursos, usar calçado adequado; logo abaixo apresentam-se os itens recomendados como: água, repelente, protetor solar e caminhar em grupos de três pessoas; à direita na base das TI continha os contatos de emergência como SAMU, polícia militar, bombeiro e defesa civil (Figura 6).

As TI visitadas proporcionaram uma compreensão das características e peculiaridades contidas na UC os quais foram abordados de maneira contextualizada com a região amazônica. A grande maioria dos alunos responderam que as PI proporcionaram uma eficiente compreensão do conteúdo contido nas TI, como é possível observar na Tabela 6; exceto o A13, que respondeu: "Parcialmente, Não dá para afirmar que contribui para a aprendizagem, pois a mesma é relativa." Cada indivíduo percebe, reage e responde diferentemente ao contato com meio. As respostas ou manifestações são resultado das percepções, dos processos cognitivos, julgamentos e expectativas de cada um, estas manifestações afetam a conduta, muitas vezes, de forma inconsciente (PALMA, 2005). Presume-se que o termo usado "relativo" esteja no sentido de que o aprendizado do aluno está condicionado a percepção de cada um. 
Tabela 6: Relatos de 15 (quinze) alunos quanto a importância das PI para a compreensão do conteúdo contido nas TI.

\begin{tabular}{l|l}
\hline A1 & $\begin{array}{l}\text { "Pois, a placa está informando aquilo que vamos ver os cuidados que precisamos ter ao entrar na } \\
\text { trilha." }\end{array}$ \\
\hline A3 & $\begin{array}{l}\text { "As placas são ótimas para nos preparar para as trilhas, tanto nos cuidados, como nas dificuldades. } \\
\text { Também há informações sobre o tipo de solo da área e o que podemos encontrar em cada tipo." }\end{array}$ \\
\hline A4 & $\begin{array}{l}\text { "A floresta Amazônica é diversa, então é muito importante as placas interpretativas para nos infor- } \\
\text { mar particularidades daquela trilha como dificuldades, solo, animais e o que observar." }\end{array}$ \\
\hline A5 & $\begin{array}{l}\text { "Com as placas interpretativas a absorção de informações fica mais fácil e melhor, além de incenti- } \\
\text { var e aguar a curiosidade e não deixar nenhum recurso natural passar despercebido." }\end{array}$ \\
\hline A7 & $\begin{array}{l}\text { "É de suma importância parta melhor compreensão dos recursos ali encontrados para orientação } \\
\text { do visitante, já que é uma área reflorestada e de abrigo para diversos animais e em local urbano e } \\
\text { como está se relaciona." }\end{array}$ \\
\hline A9 & $\begin{array}{l}\text { "As placas interpretativas fornecem informações importantes no que diz respeito ao que está pre- } \\
\text { sente nas trilhas e abre a mente para uma melhor reflexão das observações feitas." }\end{array}$ \\
\hline A10 & $\begin{array}{l}\text { "Sim, pois as trilhas interpretativas podem ser uma ferramenta importante na aprendizagem signi- } \\
\text { ficativa de discentes, explorando as vivências práticas sobre o conteúdo que é visto na teoria em } \\
\text { sala de aula." }\end{array}$ \\
\hline A11 & "Sim, proporciona a sensibilização dos alunos no que se refere as questões ambientais." \\
\hline A12 & "Sim, está relacionada aos conteúdos transversais e favorece a relação professor aluno através das \\
experiências das trilhas."
\end{tabular}

Fonte: Dados da pesquisa (2020).

O fato de os alunos alcançarem uma melhor compreensão do conteúdo de EA com o auxílio das PI nas TI foi também observado em outros estudos com quanto ao aprendizado dos alunos (SANTOS; FLORES; ZANIN, 2012; ARAÚJO, 2013; COSTA, et al., 2014). A sequência didática utilizada demonstrou proporcionar o aprendizado eficiente dos alunos, o que nos leva a sugerir que pode ser implantada em outras trilhas associada a outros componentes curriculares. Muitos estudos com trilhas vêm sendo elaborados e comprovam o aprendizado dos alunos, porém em sua maioria são voltados a Educação Ambiental e não para conteúdos ecológicos específicos. As observações feitas por Santos e Silva (2015) nos mostram que o uso de trilhas em ambientes urbanos e naturais, apesar de crescentes em eventos científicos, é utilizado para desenvolver atividades, mas sem utilizar esses “espaços 
como espaços adjacentes a sala de aula, rico de informações e imagens reais para ensinar Ciências".

\section{Considerações finais}

As TI em UC demonstraram ser eficientes espaços pedagógicos para o processo de ensino e aprendizagem de EA a partir da utilização dos principais PA e, principalmente, do contato direto do aluno com a flora, solo e recurso hídrico.

As TER, TPT, TTPI, TVP, TRSF e TEA apresentam contextos teóricos e práticos característicos do Bioma Amazônia que podem ser utilizados por alunos e professores na compreensão de conteúdos ecológicos.

Percebemos que os alunos conseguiram compreender os conteúdos ecológicos, impossíveis de serem compreendidos uma aula formal em sala de aula, pois as vivencias em cada TI foram cientificamente enriquecedoras despertando valor moral, consciência crítica e percepção individual frente aos vários desafios que o Bioma Amazônia enfrenta para manter sua biodiversidade inalterada.

A sequência didática experenciada demonstrou ser eficaz para as atividades desenvolvidas nas TI, permitindo o professor planejar, problematizar, intervir e atingir os objetivos pretendidos, podendo ser utilizada como modelo para outras pesquisas, já que os alunos foram protagonistas ao longo de todo as etapas da pesquisa.

O produto educacional elaborado contribuiu para um novo olhar a ser concebido para as UC em termos de utilização, colaborando para a instrumentalização de outros espaços com potencial para o ensino, bem como para o desenvolvimento de aulas mais participativas.

Um processo de ensino e aprendizagem integrado e regionalizado com o objeto de estudo tem grande potencial de despertar maior interesse dos alunos, estimular a percepção, facilitar a compreensão e consolidar atitudes de preservação e sustentabilidade ambiental. 


\section{Interpretive trails in conservation unit: pedagogical space for teaching ecology}

\section{Abstract}

The use of Interpretative Trails (IT) in Conservation Units (CU) has been used in basic and higher education as a viable alternative for ecological content. The objective of the research was to investigate the teaching and learning of Ecology of Amazonian (EA) through the use of IT in UC, valuing its point (s) of attractiveness (s) and the student's contact with the flora, soil and water resource. The methodology used had a qualitative approach and used a didactic sequence composed of scripts and field cards as guiding instruments and questionnaires with data collection mechanism. The research subjects were 15 (fifteen) students belonging to the Biological Sciences Degree Course (BSD), from Department of Chemistry, Environment and Food at the Federal Institute of Education, Science and Technology of Amazonas (IFAM, Brazil). The IT in CU demonstrated to be efficient pedagogical spaces for the teaching and learning process of EA. The students were able to understand the ecological contents, impossible to occur in a formal class in the classroom, as the experiences in each IT were scientifically enriching, awakening moral value, critical awareness and individual perception in the face of the various challenges that the Amazon Biome faces to maintain its biodiversity unchanged. The educational product elaborated contributed to a new look to be conceived for the $\mathrm{CU}$ in terms of use, collaborating for the instrumentalization of other spaces with potential for teaching, as well as for the development of more participatory classes.

Keywords: Interpretative trails. Conservation units. Didactic sequence. Ecology of amazonian.

\section{Referências}

AB'SABER, A. N. Bases para o estudo dos ecossistemas da Amazônia brasileira. Estudos Avançados, v. 16, n. 45, p. 7-30, 2002.

ANDRADE, W. J. Implantação e manejo de trilhas. In: MITRAUD, S. (Org.). Manual de ecoturismo de base comunitária: ferramentas para um planejamento responsável. Secção 2, Capítulo 2.6. WWF-Brasil, Brasília, 2003, p. 247-260.

ANDRETTA, V.; MACEDO, R.L.G.; VITORINO, M. R.; MARTINS, G. S. Sinalização de trilhas: importância e eficiência. 2006. 13p. Disponível em: <http://www.scribd.com/doc/11566793/ SINALIZACAO-DE-TRILHASIMPORTANCIA-E-EFICIENCIA>. Acessado em 10 dez. 2019.

ARAÚJO, J. N. Jardim Botânico Adolpho Ducke: uma possibilidade para a educação científica na Amazônia. Novas Perspectivas de Ensino de ciências em espaços não formais amazônicos. Manaus: UEA edições, p. 187-197, 2013.

BARDIN, L. Análise de conteúdo. 3. ed. Lisboa: Edições 70, 2016. 141p.

BARRETO, L. C. M. de S.; MARQUES, J. D. O., AZEVEDO, R. O. M. Guia para instrumentalização de trilhas interpretativas numa perspectiva de ensino e aprendizagem. Curitiba: CRV, 2019. 96p. 
BEDIM, B. P. Trilhas Interpretativas como instrumento pedagógico para a educação biológica e ambiental: reflexões. BioEd 2014. Anais eletrônicos... Rio de Janeiro: IUBS/UNESCO/LDES, 2004. Disponível em: <Disponível em: <http://www.ldes.unige.ch/bioEd/2014/pdf/bedim.pdf>. Acessado em: 15 fev. 2020.

BOTELHO, J. S.; MARQUES, J. D. O.; OLIVEIRA, A. N. S. Experimentos em laboratório para o ensino sobre solos na disciplina de geografia. Revista de Estudos e Pesquisas sobre Ensino Tecnológico, v. 5, n. 10, p. 228-248, 2019.

BOTELHO, J. S.; MARQUES, J.D.O. O ensino de solo na Geografia a partir da prática em campo. Revista de Estudos e Pesquisas sobre Ensino Tecnológico, v. 6, Edição Especial, P. 1-21, 2020.

BRASIL. Ministério da Educação. Coordenação de Aperfeiçoamento de Pessoal em Nível Superior. Documento de Área - Ensino, 2016. Disponível em: <https://pos.cepae.ufg.br/up/480/o/ DOCUMENTO_DE_AREA_ENSINO_2016_final.pdf>. Acessado em 10 jun. 2020.

CASES, M. O. (Org.), et al. Gestão de Unidades de Conservação: compartilhando uma experiência de capacitação. WWF-Brasil, Brasília, DF, Brasil. 2012. 397p.

COSTA, V. C. 2006. Propostas de manejo e planejamento ambiental de trilhas ecoturísticas: um estudo no Maciço da Pedra Branca - Município do Rio de Janeiro (RJ). Tese de Doutorado. Programa de Pós-graduação em Geografia da UFRJ. 325p.

COSTA, E. S. A.; COSTA, I. A. S.; OLIVEIRA, K. S.; MELO, A. V. Trilhas interpretativas na área verde da escola como estratégia de ensino para aprendizagem de conceitos ecológicos. Revista da SBEnBIO. n.7, v.1. Enebio e II Enebio Regional 1. Universidade do Rio Grande do Norte UFRN, 2014, p.110.

DALFOVO, M. S.; LANA, R. A.; SILVEIRA, A. Métodos quantitativos e qualitativos: um resgate teórico. Revista Interdisciplinar Científica Aplicada, v. 2, n. 3, p. 1-13, 2008.

DENZIN, N. K.; LINCOLN, Y. S. O Planejamento da pesquisa qualitativa: Teorias e abordagens. 2.ed. Porto Alegre: Artmed. 2006.432p.

DOS SANTOS, R. D.; DOS SANTOS, H. G.; KER, J. C.; DOS ANJOS, L. H. C.; SHIMIZU, S. H. Manual de descrição e coleta de solo no campo. 7.ed. Viçosa: SBCS, 2015. 101p.

EISENLOHR, P. V.; MEYER, L.; MIRANDA, P.L.S.; REZENDE, V.L. Trilhas e seu papel ecológico: o que temos aprendido e quais as perspectivas para a restauração dos ecossistemas? Rev. Hoehnea. v.40, n.3, p.407-418, 2013.

FEITOSA, A. A.; SOUSA, J. S.; ALENCAR, G. S. Trilhas ecológicas como ferramentas de educação e interpretação ambiental: um estudo de caso na Floresta Nacional de Palmares, Salvador/BA - 25 a 28/11/2. In: Anais do Congresso Brasileiro de Gestão Ambiental IV, p. 1-6, 2013. Salvador/ BA.

FERREIRA, G. Environmental education through hiking: A qualitative investigation. Environmental Education Research, v. 4, n. 2, p. 177-185, 1998.

FILHO, M. V. C.; AMARAL, A.A.; ABREU, K.M.P. Trilhas ecológicas como instrumento de sensibilização para questões ambientais. Enciclopédia Biosfera, v.10, n.18, p. 36-35, 2014.

FRANZINELli, E.; IGREJA, H. Sítios geológicos e Paleontológicos do Brasil. Brasília: CPRM, 2013. p.1-20. 
FREITAS, M. S. de; MARQUES, J. D. O.; SOUZA, A. J. de. Explorando atividade de campo em ecossistemas amazônicos para discutir conceitos relacionados às mudanças climáticas globais. Revista Experiência em Ensino de Ciências, v. 16, p. 89-102, 2020.

GIL, A. C. Como elaborar projeto de pesquisa. 3. ed. São Paulo: Atlas, 1991. 101p.

GONZAGA, V. L.; MARTINS, L. F. S. Planejamento do traçado de uma trilha interpretativa por meio da caracterização florística. Revista Janus, v.8, n. 13, p. 59-70, 2011.

ICMBIO. Instituto Chico Mendes de Conservação da Biodiversidade. Manual de Sinalização. Disponível em: <http:/www.icmbio.gov.br/portal/images/stories/comunicacao/publicacoes/ publicacoesdiversas/manual_de_sinalizacao_unidades_de_conservacao_federais_do_brasil_2018.pdf>. Acessado em: 10 fev. 2020.

IKEMOTO, S. M. As Trilhas Tnterpretativas e sua relevância para promoção da conservação: Trilha do Jequitibá, Parque Estadual dos Três Picos (PETP), RJ. Dissertação de Mestrado. Curso de Pós-Graduação em Ciência Ambiental da Universidade Federal Fluminense, 2008. 170p.

LIMA, E. S dos S.; MARQUES, J. D. O. Proposta didática para o ensino de meio ambiente e água. Curitiba: CRV, 2019. 93p.

LUIZÃO, F. J. Ciclos de nutrientes na Amazônia: respostas às mudanças ambientais e climáticas. Ciência Cultura, v.59 n.3, p. 31-36, 2007.

MARQUES, J. D. O.; OLIVEIRA, A. N. S.; PAES, L. da S. Prática de campo nas aulas de ecologia: uma análise a partir de ecossistemas amazônicos. Experiências em Ensino de Ciências, v.14, p. 299-319, 2019.

MARQUES, J. D. O.; LUIZÃO, F. J.; TEIXEIRA, W. G.; VITEL, C.M.; MARQUES, E.M. de A. Soil organic carbon, carbon stock and their relationships to physical attributes under forest soils in Central Amazonia. Revista Árvore, v.40, p.197-208, 2016.

MMA. Ministério do Meio Ambiente. Diretrizes para a Visitação em Unidades de Conservação. Brasília: Ministério do Meio Ambiente, 2006. 65p.

MENEZES, P. de C. Parques do Brasil Sinalização de Trilhas: Manual Prático, 68p., WWF-Brasil. 2015. Disponível em: <http://d3nehc6yl9qzo4.cloudfront.net/downloads/wwf_manual_sinalizacao_trilhas.pdf>. Acessado em: nov. 2019.

MUNSELL COLOR. Munsell Soil color charts. New Windsor: MCBETH, 1994. 25p.

NELSON, S. P. Uso público nas unidades de conservação. In: CASES, M.O. Gestão de Unidades de Conservação: compartilhando uma experiência de capacitação. 2012. 396p., WWF-Brasil, Brasília, DF, Brasil.

OLIVEIRA, S. C. C.; MELO, R. S. As trilhas do Jardim Botânico Benjamim Maranhão (João Pessoa-PB) como recurso para interpretação ambiental. Caderno virtual de turismo, v. 9, n. 2, 2009.

OLIVEIRA, A. P. L.; CORREIA, M. D. Aula de campo como mecanismo facilitador do ensino-aprendizagem sobre os ecossistemas recifais em alagoas. Alexandria: Revista de Educação em Ciência e Tecnologia, v. 6, n. 2, p. 163-190, 2013.

OLIVEIRA, A. N. S.; MARQUES, J. D. Aula de campo no ensino de solos. Revista de Estudos e Pesquisas sobre Ensino Tecnológico (EDUCITEC), v. 3, n. 05, p.33-47 2017.

PAIVA, A. C.; FRANÇA, T. L. Trilhas interpretativas, Reconhecendo os elos com a educação física. Rev. Bras. Cienc. Esporte, Campinas, v. 28, n. 3, p. 109-124, 2007. 
PALMA, I. R. Análise da percepção ambiental como instrumento ao planejamento da educação ambiental. Dissertação (Mestrado em Engenharia) - Escola de Engenharia, Universidade Federal do Rio Grande do Sul. 2005. 83p.

PEREIRA, I. S. D.; MACIEL, C. P.; COUTINHO, R. R.; BURLA, R. S. Princípios para a criação de uma trilha ecológica interpretativa, com elementos socioculturais regionais, em um fragmento de restinga no município de São Francisco de Itabapoana. Boletim do Observatório Ambiental Alberto Ribeiro Lamego, v. 8, n. 2, p. 195-216, 2015.

PRONEA. Programa nacional de educação ambiental. Ministério do Meio Ambiente, Diretoria de Educação Ambiental; Ministério da Educação. Coordenação Geral de Educação Ambiental. 3.ed - Brasília: Ministério do Meio Ambiente, 2005.

PRONEA. Programa nacional de educação ambiental. Ministério do Meio Ambiente, Diretoria de Educação Ambiental; Ministério da Educação. Coordenação Geral de Educação Ambiental. 4.ed - Brasília: Ministério do Meio Ambiente, 2014.

PROJETO DOCES MATAS. Manual de introdução à interpretação ambiental. Belo Horizonte, 2002. 108 p.

SANTOS, M. C.; FLORES, M. D.; ZANIN, E. M. Educação ambiental por meio de trilhas ecológicas interpretativas com alunos nees. Revista Monografias Ambientais, v. 5, n. 5, p. 982-991, 2012.

SANTOS, F. C.; SILVA, F. A. R. As trilhas ecológicas e o ensino de ciências: Análises dos últimos anais dos encontros de Ensino de Ciências, Biologia e Educação Ambiental no Brasil. Anais do X Encontro Nacional de Pesquisa em Educação em Ciências - X ENPEC. Águas de Lindóia, SP -24 a 27 de novembro de 2015.

SANTOS, N. C. C dos. O ensino de ecologia nos cursos de ciências biológicas: da sala de aula ao campo. Programa de Pós Graduação em Ensino Tecnológico. Instituto Federal de Educação, Ciência e Tecnologia do Amazonas - IFAM. Dissertação de Mestrado. IFAM, 2020. 160p.

SENICIATO, T.; CAVASSAN, O. Aulas de campo em ambientes naturais e aprendizagem em ciências: um estudo com alunos do ensino fundamental. Ciência \& Educação (Bauru), p. 133147, 2004.

SILVA, D. M. A caracterização da interpretação ambiental pelo conteúdo das mensagens: análise da atividade de um guia do parque estadual mata dos godoy (LONDRINA/PR). 2012. Dissertação. Universidade estadual de londrina, LONDRINA- PR, 2012. 92p.

SIQUEIRA, L. F. Trilhas interpretativas s: uma vertente responsável do (eco) turismo. Caderno Virtual de turismo, v. 4, n. 4, p. 79-87, 2006.

TEIXEIRA, P. M. M.; MEGID NETO, J. Investigando a pesquisa educacional: Um estudo enfocando dissertações e teses sobre o ensino de Biologia no Brasil. Investigações em 14 Ensino de Ciências, v.11, n.2, pp. 261-282, 2006. Disponível em: <https://www.if.ufrgs.br/cref/ojs/index. php/ienci/article/view/496/299>. Acessado em 18 mar. 2020.

VALENTI, M. W.; OLIVEIRA, H. T. de; DODONOV, P.; SILVA, M. M. Educação ambiental em unidades de conservação: políticas públicas e a prática educativa. Educação em Revista, v. 28, p.267-288, 2012. 